NBER WORKING PAPER SERIES

\title{
THE SUPPLY AND DEMAND OF S\&P 500 PUT OPTIONS
}

\author{
George M. Constantinides \\ Lei Lian \\ Working Paper 21161 \\ http://www.nber.org/papers/w21161
}

\section{NATIONAL BUREAU OF ECONOMIC RESEARCH 1050 Massachusetts Avenue Cambridge, MA 02138}

May 2015

We thank David Bates, Michal Czerwonko, Zhiguo He, Jens Jackwerth, Nikunj Kapadia, Stylianos Perrakis, Alexi Savov, Myron Scholes, and Dacheng Xiu for helpful comments. Constantinides acknowledges financial support from the Center for Research in Security Prices of the University of Chicago, Booth School of Business. The views expressed herein are those of the authors and do not necessarily reflect the views of the National Bureau of Economic Research.

NBER working papers are circulated for discussion and comment purposes. They have not been peerreviewed or been subject to the review by the NBER Board of Directors that accompanies official NBER publications.

(C) 2015 by George M. Constantinides and Lei Lian. All rights reserved. Short sections of text, not to exceed two paragraphs, may be quoted without explicit permission provided that full credit, including (C) notice, is given to the source. 
The Supply and Demand of S\&P 500 Put Options

George M. Constantinides and Lei Lian

NBER Working Paper No. 21161

May 2015

JEL No. G10,G12,G13,G23

\begin{abstract}
$\underline{\text { ABSTRACT }}$
We document that the implied volatility skew of S\&P 500 index puts is non-decreasing in the disaster index and risk-neutral variance, contrary to the implications of a broad class of no-arbitrage models. The key to the puzzle lies in recognizing that, as the disaster risk increases, customers demand more puts as insurance while market makers become more credit-constrained in writing puts. The resulting increase in the equilibrium price is more pronounced in out-of-the-money than in-the-money puts, thereby steepening the implied volatility skew and resolving the puzzle. Consistent with the data, the model also implies that the equilibrium net buy of puts is decreasing in the disaster index, variance, and their price. The data shows a significant decreasing relationship between the IV skew and the net buy and no relationship in other periods, also explained by the model.
\end{abstract}

George M. Constantinides

The University of Chicago

Booth School of Business

5807 South Woodlawn Avenue

Chicago, IL 60637

and NBER

gmc@ChicagoBooth.edu

Lei Lian

Isenberg School of Management

UMass Amherst

Massachussets

USA

sabrinalian2007@gmail.com 


\section{Introduction}

We document that the implied volatility skew of S\&P 500 index puts, defined as the implied volatility (IV) of out-of-the money (OTM) puts minus the implied volatility of at-the-money (ATM) puts is non-decreasing in the disaster index and risk-neutral (RN) variance. We dub this the "skew response puzzle" because, as we demonstrate, a broad class of widely used no-arbitrage models for pricing options that allow for stochastic volatility and price jumps implies that the skew is a decreasing function of the disaster index and $R N$ variance.

We address the skew response puzzle by departing from the class of no-arbitrage models of pricing options and endogenizing the supply and demand of index puts. The key departure lies in recognizing that the principal writers of index puts are market makers who face credit constraints which are modeled here as an exogenously imposed Value-at-Risk (VaR) constraint. The model captures the scenario where risk neutral market makers write "overpriced" index puts to maximize their expected profit, subject to their credit constraint, while risk averse customers buy the index to maximize their expected utility and hedge their exposure to downside risk by buying index puts. The key to the puzzle lies in recognizing that, as the disaster risk and variance increase, customers demand more puts as insurance while market makers become more credit-constrained in writing puts. The resulting increase in the equilibrium price is more pronounced in out-of-the-money than in at-the-money puts, thereby steepening the IV skew and resolving the puzzle.

We define the "net buy" by public customers of index options of given moneyness and maturity in a month as the average of the daily executed total buy orders by public customers and firms (to open new positions or close existing ones) during the month minus their daily executed total sell orders. The net buy is the equilibrium quantity determined at the intersection of the supply and demand curves, unlike some earlier literature that treats the 
net buy as a proxy for demand. The shift in the supply and demand for S\&P 500 put options not only explains the IV skew puzzle but also explains a novel set of empirical observations about the net buy of puts which challenge earlier models. In particular, these observations suggest that the demand pressure hypothesis alone is deficient in explaining the net buy of puts. The supply shift by credit-constrained market makers plays an important role in explaining the net buy of puts. Our model provides implications regarding the net buy that are born out in the data.

The model and the data consistently imply that the net buy of puts by public customers is decreasing in the $R N$ variance and disaster index. The intuition is that, when the $R N$ variance and/or disaster index increase, public customers like to buy more puts as insurance but market makers become more credit-constrained. That is, both the supply and demand curves shift. The supply shift turns out to be the driving factor in the decrease in the equilibrium net buy of puts.

We also address the model implications regarding the relationship between the net buy of puts and their price. The model implies that the net buy of OTM and ATM puts is decreasing in their price. The intuition is the same as above. When the $R N$ variance and/or disaster index increase, public customers like to buy more puts as insurance but market makers become more credit-constrained. The supply shift turns out to be the driving factor in the decrease in the equilibrium net buy and the price increase of OTM puts. These implications are born out in the data.

Our model implications regarding the relationship between the net buy and the IV skew of puts are also consistent with the data. The data shows no significant relationship in general except a decreasing relationship during the financial crisis. The model implies that the net buy of OTM puts increases with the IV skew when the $R N$ variance is fixed and we vary the disaster risk. The net buy of OTM puts decreases the skew with when we fix the disaster 
risk and vary the $R N$ variance. For ATM puts, our model implies that the net buy decreases the skew when we vary the disaster risk and fix the $R N$ variance, but may either increase or decrease with the skew when we fix the disaster risk and vary the $R N$ variance. Given the correlation between the $R N$ variance and disaster index, the relationship between the IV skew and the net buy of OTM and ATM puts is complex.

Finally, we confirm the robustness of our results by constructing the net buy of OTM and ATM options by using different ranges of moneyness and maturity; by de-trending the net buy in different ways; and by studying the relation of the net buy with the $R N$ variance, disaster index, option prices, and IV skew for different sub-periods, before, during, and after the financial crisis.

Our paper relates to the extensive literature on dealers' and intermediaries' credit constraints and funding liquidity in the form of VaR, margin, and leverage constraints. Representative examples include Adrian and Shin (2014), Brunnermeier and Pedersen (2009), Danielsson, Shin, and Zigrand (2004), Gromb and Vayanos (2002), He and Krishnamurthy (2013), Shleifer and Vishny (1997), and Thurner, Farmer, and Gaenakoplos (2012). In particular, Adrian and Shin (2014) provided evidence that the VaR constraint of financial intermediaries, normalized by equity, is constant over the financial cycle.

Specific to the pricing of options, this literature examines the extent to which traders' and intermediaries' credit constraints and funding liquidity may explain difficulties with noarbitrage models of option pricing. In a prescient essay, Bates (2003) stated: "Relatively few option market makers apparently have been writing crash insurance for a broad array of money managers, which may pose institutional difficulties for the risk-sharing assumptions underlying representative agent models. On the demand side, it is conceivable that especially risk-averse money managers have been willing to buy crash insurance that never seems to pay off." Bollen and Whaley (2004) examined the relation between the net buying pressure 
of index options and found that the IV of index options is directly related to the buying pressure for index puts.

Gârleanu, Pedersen, and Poteshman (2009) introduced exogenous shifts in the demand by public customers for index options. An exogenous positive shift in the demand for a certain option increases its price because risk-averse market-makers are unable to perfectly hedge their inventories and their supply of options is less than perfectly elastic. In Section 6, we present empirical evidence that the net buy of both OTM and ATM S\&P 500 puts is decreasing in the respective put price, suggesting that the demand pressure hypothesis alone does not explain the data. Whereas the Gârleanu et al. (2009) model does not address the skew response puzzle, their Proposition 4 states that an exogenous positive shift in the demand for a certain OTM put has a bigger pricing effect on the demand of deep OTM puts than on slightly OTM puts, that is, the IV skew unambiguously becomes steeper with higher net buy. In Section 6, we present empirical evidence that the IV skew is never increasing in the net buy of puts and is actually decreasing during the financial crisis. These considerations motivate the introduction of supply shifts, in addition to demand shifts, in the options market.

Chen, Joslin, and Ni (2014) modeled the market makers' risk aversion and credit constraints as an increasing function of the disaster risk. Their model implies that the demand for crash insurance, proxied by the net buy of deep OTM puts, predicts the return on the S\&P 500 index. Our model significantly differs from that of Chen et al. (2014). First, our model specifically addresses the supply and demand shifts of put options across moneyness and addresses a comprehensive set of stylized facts regarding the implied volatility skew and the net buy of puts. Second, we model the market makers' credit constraint as a VaR constraint that is driven by both the disaster risk and variance, unlike the credit constraint in the Chen et al. (2014) model that is driven by disaster risk alone. 
Our paper also relates to the extensive literature on stochastic dominance violations by option prices. Constantinides, Czerwonko, Jackwerth, and Perrakis (2011) and Constantinides, Jackwerth, and Perrakis (2009) showed that OTM European calls on the S\&P 500 index and OTM American calls on the S\&P 500 index futures frequently imply stochastic dominance violations: any risk averse investor who invests in a portfolio of the index and the risk free asset increases his expected utility by writing OTM "overpriced" calls. By contrast, these papers found that OTM puts on the S\&P 500 index and the index futures rarely imply stochastic dominance violations: a risk averse investor who invests in a portfolio of the index and the risk free asset rarely increases his expected utility by writing OTM "overpriced" puts. These findings motivate our focus on OTM puts, as opposed to OTM calls. In our paper, we model investors as buyers, as opposed to sellers, of OTM puts to hedge the downside risk of their investment in the market portfolio. This modelling choice is consistent with the above findings on stochastic dominance.

Our paper also relates to the extensively literature on no-arbitrage option pricing models. Examples include Andresen, Benzoni, and Lund (2002), Andersen, Fusari, and Todorov (2015a,b), Bakshi, Cao, and Chen (1997), Bates (2000, 2006), Broadie, Chernov, and Johannes (2007), Chernov, Gallant, Ghysels, and Tauchen (2003), Duffie, Pan, and Singleton (2000), Eraker (2004), Eraker, Johannes, and Polson (2003), Heston (1993), Heston, Christoffersen, and Jacobs (2009), Lian (2014), and Pan (2002).

Finally, our paper relates to the literature that addresses the cross-sectional variation in index option returns. Examples include Buraschi and Jackwerth (2001), Cao and Huang (2008), Carverhill, Dyrting, and Cheuk (2009), Constantinides, Jackwerth, and Savov (2013), and Jones (2006). Specifically, Constantinides et al. (2013) demonstrated that any one of crisis-related factors incorporating price jumps, volatility jumps, and liquidity, along with the market, explains the cross-sectional variation in index option returns. These findings 
motivate our focus on disaster risk and liquidity constrains in the form of VaR constraints.

The paper is organized as follows. In Section 2, we define the variables and describe the data. In Section 3, we present the skew response puzzle. The model is stated in Section 4. In Section 5, we demonstrate that the model explains the IV skew puzzle. In Section 6, we discuss the model implications on the net buy by public customers and relate them to the empirical evidence. In Section 7, we discuss extensions of the model and conclude. Derivations are relegated to the appendix.

\section{Definition of the Variables and Description of the Data}

\subsection{Definition of the Variables}

The Implied volatility $(I V)$ is the Black-Scholes implied volatility. Moneyness is defined as the ratio of the strike price to the index price, $\mathrm{K} / \mathrm{S}$. We compute the model-implied skew as the difference between the IV of a one-month put with moneyness 0.85 and the IV of a one-month ATM put. We compute the empirical skew from all ATM S\&P 500 put options with moneyness 0.97-1.03 and maturity 15-60 days; and OTM puts with moneyness 0.8-0.9 and maturity 15-60 days. Each day, we first compute the average IV of ATM and OTM puts. We then calculate the skew as the difference between the average IV of the OTM and ATM put options. Finally, we average these slopes across all trading days of the given calendar month.

The Risk Neutral (RN) Variance, also known as the squared VIX, is defined as in Britten- 
Jones and Neuberger (2000):

$$
R N \text { Variance }=\frac{2 e^{r T}}{T}\left[\int_{K>S_{0}} \frac{C\left(S_{0} ; K, T\right)}{K^{2}} d K+\int_{K \leq S_{0}} \frac{P\left(S_{0} ; K, T\right)}{K^{2}} d K\right]
$$

where $S_{0}$ is the index price at the beginning of the month; $K$ is the strike; $T$ is one month; $C\left(S_{0} ; K, T\right)$ is the European call price; $P\left(S_{0} ; K, T\right)$ is the European put price; and is the continuously-compounded risk free rate.

Bakshi, Kapadia, and Madan (2003) derived the price of a volatility contract as

$$
\frac{2 e^{r T}}{T}\left[\int_{K>S_{0}} \frac{\left(1-K / S_{0}\right) C\left(S_{0} ; K, T\right)}{K^{2}} d K+\int_{K \leq S_{0}} \frac{\left(1-K / S_{0}\right) P\left(S_{0} ; K, T\right)}{K^{2}} d K\right]
$$

Du and Kapadia (2012) showed that this is a variance measure that is more inclusive of price jumps than the $R N$ variance.

We define the Disaster Index as in Du and Kapadia (2012):

$$
\begin{aligned}
& \text { Disaster Index } \\
& =\frac{2 e^{r T}}{T}\left[\int_{K>S_{0}} \frac{\left(1-K / S_{0}\right) C\left(S_{0} ; K, T\right)}{K^{2}} d K+\int_{K \leq S_{0}} \frac{\left(1-K / S_{0}\right) P\left(S_{0} ; K, T\right)}{K^{2}} d K\right] \\
& +\frac{2}{T}\left(e^{r T}-1-r T\right)-\frac{1}{T} E^{Q}\left(S_{T} / S_{0}\right)-R N \text { Variance }
\end{aligned}
$$

We compute the $R N$ variance and disaster index from available option prices. First, we extract the B-S implied volatility from the B-S implied volatility surface at the two available maturities closest to 30 calendar days. Cubic splines are first applied in the moneyness dimension, defined as strike price divided by stock price and ranging from 0.003 to 3 , to interpolate the B-S implied volatility for each moneyness of a fixed maturity. Therefore, the interpolated implied volatility as a smooth function of moneyness is obtained for each of 
the two option maturities. Next, for each moneyness in the previous step, we apply linear interpolation using the B-S implied volatility of the two maturities to achieve the B-S implied volatility at 30 days of maturity.

We define the model-implied net buy of puts as the model-implied number of puts purchased by the customer at the beginning of the period. We construct our empirical measure of the monthly net buy of S\&P 500 put options by customers as follows. The daily net buy of a given option on a given trading day is the sum of the open buy and close buy minus the sum of open sell and close sell on that day by customers. We calculate the monthly net buy of options for two moneyness ranges, OTM (0.8-0.9) and ATM (0.97-1.03, and maturity 1560 days. We next compute the monthly net buy for a given target moneyness and maturity as the average of the daily net buy across all trading days of the given calendar month of all options with the targeted moneyness and maturity range. Our measure of the monthly net buy is the de-trended net buy that is computed as the realized net buy of a certain category of options, such as OTM puts, dividend by the total trading volume of put options in this maturity category.

We also de-trended the net buy by using the total trading volume of all puts in the same moneyness and maturity, or total call or puts at the same maturity or same moneyness category, and obtained similar results, not reported in the paper. We also considered an alternative definition of net buy that includes the net buy by proprietary firms, in addition to the net buy by customers. The results remained virtually unchanged because the net buy by firms is a small fraction of the total net buy and are not reported in the paper. 


\subsection{Description of the Data}

The data for computing the net option buy is obtained from the Chicago Board Options Exchange (CBOE) from the beginning of 1996 to the end of 2012. The data consists of a daily record of traded contract volumes on open-buy, open-sell, close-buy, and close-sell for each option by three types of public customers plus proprietary firms. The public customers include small, medium, and large customers. We compute the net buy of each of these groups of agents as the long interest minus the short interest of both open and close to trade. According to the order size, an order size greater than 200 contracts is classified as orders of a large customer, the order size between 101-200 contracts is classified as orders of a median customer, and the order size less than 100 contracts is classified as the order of a small customer. Small customers on S\&P 500 options are not necessarily retail traders. Instead, Chen, Goslin, and $\mathrm{Ni}$ (2014) showed that the small customers who sold deep OTM S\&P 500 puts are institutional traders. Our measure of net buy is the sum of the net buy by the three categories of customers.

Option prices are obtained from a high-frequency dataset provided by the Chicago Board Options Exchange (CBOE). It contains intra-day trades and quotes of the S\&P 500 options. The minute-level data of the index values of the S\&P 500 index is from Tick Data Inc. The recorded underlying S\&P 500 index values for each option are the corresponding index levels at the moment when the option bid-ask quote is recorded. The dividend yield of S\&P 500 index is provided by OptionMetrics. For a given option, we extract the implied interest rate from the put-call parity as in Constantinides, Jackwerth, and Savov (2013). 


\section{The Skew Response Puzzle}

A broad class of widely used no-arbitrage models extends the original Black and Scholes (1973) and Merton (1973) model of pricing options by allowing for stochastic volatility and jumps in the price and volatility. The Bates (2006) model, a representative model in this class, is specified as follows in terms of the RN probability measure:

$$
\begin{aligned}
d \log \left(S_{t}\right) & \left.=\left(r_{t}-q_{t}-\frac{V_{t}}{2}-\left(\lambda_{0}+\lambda_{1} V_{t}\right) \mu\right) d t+\sqrt{(} V_{t}\right) d W_{1 t}+J_{t} d N_{t} \\
d V_{t} & =k\left(\theta-V_{t}\right) d t+\sigma \sqrt{V_{t}} d W_{2 t}
\end{aligned}
$$

where $d \log \left(S_{t}\right)$ is the instantaneous stock market log return; $r_{t}$ is the risk free rate; $q_{t}$ is the dividend yield; $V_{t}$ is the instantaneous variance conditional upon no jumps; $d W_{1 t}$ and $d W_{2 t}$ are Wiener processes with correlation $\rho ; N_{t}$ is a Poisson counter with intensity $\lambda_{0}+\lambda_{1} V_{t}$ for the incidence of jumps; and $J_{t} \sim N\left(\mu, \sigma_{J}^{2}\right)$ is a random Gaussian jump. The empirical correlation between the disaster risk and the $R N$ variance is around 0.96 , which indicates that a linear relationship between the disaster probability and $R N$ variance is reasonable.

We estimate the model with daily S\&P 500 call and put prices over the period 1996:Q12012:Q4. The moneyness ranges from 0.85 to 1.15 and the maturity ranges from 15 to 360 days. We proxy the latent state variable $V_{t}$ with the $\mathrm{RN}$ variance estimated from the crosssection of S\&P 500 options maturing in 30 days. ${ }^{1}$ We estimate the model by minimizing the sum of squared errors of all options, where the error of one option is defined as the observed IV minus the model-implied IV. The parameter estimates are $\sigma=0.27, \lambda_{0}=2.89 E-9$, $\lambda_{1}=4.24, \mu=-6.25, \sigma_{J}=14.99, \kappa=0.038, \theta=0.95, \rho=-0.79$. Since $\lambda_{1}>0$, the model

\footnotetext{
${ }^{1}$ We justify ex post the procedure of proxying the latent state variable $V_{t}$ with the squared $R N$ implied volatility as follows. We use the point estimates of the parameters to calculate the model-implied option prices at different values of the state variable $V_{t}$, calculate the $R N$ implied volatility, and regress the RN implied volatility against $\sqrt{V_{t}}$. The regression coefficient is 0.857 and the intercept is 0.00677 , thereby justifying the commonly-used estimation procedure of proxying the latent state variable $\sqrt{V_{t}}$ with the squared $R N$ implied volatility.
} 
has the plausible implication that the probability of disaster is increasing in the variance. The parameter estimates are reported using a daily time interval and scaling the stock return by 100, as is conventional in the time-series literature, such as Broadie et al. (2007), Eraker (2002), and Lian (2014).

In figure 1, we display the IV skew as a function of the disaster index and the $R N$ variance, implied by the Bates (2006) model. The skew is decreasing in the $R N$ variance. The flattening skew is a common feature of this class of models. The intuition is that the distinction between the IV of OTM puts and the ATM puts diminishes and the skew flattens as the $R N$ variance increases. The skew is decreasing also in the disaster index. If the $R N$ variance were kept constant, the IV skew would be increasing in the disaster risk. The reason that the IV skew is decreasing in the disaster index is that in the Bates (2006) model the $R N$ variance and the disaster risk are perfectly positively correlated. The decreasing pattern indicates that the disaster risk impacts the IV skew less than the $R N$ variance does in the no-arbitrage model. It would be unrealistic to construct a no-arbitrage model where the $R N$ variance and disaster risk are either uncorrelated or negatively correlated because, as figure 2 illustrates, the $R N$ variance and the disaster risk are strongly positively correlated in the data.

We also estimate the Bates (2006) model for the sub-periods before, during, and after the 2008 crisis, and obtain the same pattern for the IV skew. We note that the regularities displayed in figure 1 are invariant to assumptions about the price of volatility risk and disaster risk because the Bates (2006) model is stated here in terms of only the risk neutral probability measure without reference to the physical measure.

[Figures 1 and 2 here]

We verified similar results in other no-arbitrage models. The model in Andersen et al. (2015a) is more flexible with a multifactor volatility process and jumps in price and volatility 
processes. They modeled the jump intensity as being linear in the volatility as in Bates (2006). Their model has similar implications: the IV skew is decreasing in both the disaster index and the $R N$ variance. Naturally, it remains an open question whether a plausible no-arbitrage model exists that displays a non-decreasing IV skew as a function of either the disaster index or the $R N$ variance and also captures the strong positive correlation between the disaster index and the $R N$ variance.

The puzzle is that the implications of the no-arbitrage model in figure 1 are inconsistent with the empirical evidence. In figure 3 , we display the empirical IV skew of S\&P 500 options as a function of the $R N$ variance and disaster index over the time period January 1996-Decamber 2012; before the financial crisis, January 1996-November 2007; during the crisis, December 2007-June 2009; and after the crisis, July 2009-December 2012. The figure shows that the IV skew is non-decreasing in the disaster index and $R N$ variance. (See also the regression results in Table 1 , discussed later on.) This observation motivates us to propose a model for the pricing of puts that incorporates credit constraints faced by market makers.

[Figure 3 here]

In the following sections, we address the skew response puzzle and the observed behavior of the net buy by departing from the class of no-arbitrage models of pricing options and endogenizing their supply and demand. The key departure lies in recognizing that the principal writers of index puts are market makers who face credit constraints, modeled here as an exogenously imposed Value-at-Risk (VaR) constraint. In figure 4, we present the time series of two measures of financial constraints, noise and the TED spread. The TED spread is the difference between the 3-month LIBOR and the 3-month T-bill rate. The noise is a fixed-income market based funding liquidity measure by $\mathrm{Hu}$, Pan, and Wang (2013). The financial constraints vary over time and peak during the financial crisis. After successfully addressing the skew response puzzle, we also show that our model implications about the 
relationship between the net buy of puts and the disaster index, $R N$ variance, put price, and IV skew are consistent with the data.

[Figure 4 here]

\section{A Model of the Supply and Demand for Index Put Options}

We consider a one-period model. Agents trade at the beginning of the period and consume at the end of the period. There are three traded assets: risk free bonds, the market index (stock), and one-period puts of given moneyness. Bonds are elastically supplied. Each bond pays one unit of the consumption good at the end of the period. The bond price is the numeraire at the beginning of the period. Therefore, without loss of generality, the risk free rate is zero.

Shares of stock are elastically supplied. A share of stock pays $S$ units of the consumption good at the end of the period. A disaster occurs with probability $p, 0<p<1$. In the no-disaster state, $S=e^{\mu+\sigma Z}$ and in the disaster state, $S=e^{\mu_{J}+\sigma_{J} Z}$, where $Z \sim N(0,1)$ and $\mu, \mu_{J}, \sigma, \sigma_{J}$ are parameters. The stock price at the beginning of the period is exogenous and equals one. We assume that the expected equity premium is positive, $(1-p) e^{\mu+\sigma Z}+$ $p e^{\mu_{J}+\sigma_{J} Z}>1$.

The parameters $p, \mu, \mu_{J}, \sigma$ and $\sigma_{J}$ are specific to a given month. We allow the $R N$ variance and disaster index to differ across months. Therefore, different months are associated with different parameter values. We make no assumptions about the time-series process of these parameters but estimate the disaster index and $R N$ variance from the cross-section of puts prices each month. 
The model-implied variance of $\log (S)$ on the real probability measure is

$$
\begin{aligned}
\operatorname{var}\{\log (S)\} & =E\left[(1-p)\left\{p\left(\mu-\mu_{J}\right)+\sigma Z\right\}^{2}+p\left\{-p\left(\mu-\mu_{J}\right)+\sigma_{J} Z\right\}^{2}\right] \\
& =(1-p) p\left(\mu-\mu_{J}\right)^{2}+(1-p) \sigma^{2}+p \sigma_{J}^{2}
\end{aligned}
$$

Since the model-implied variance reduces to $\sigma^{2}$, if we suppress disasters $(p=0)$, we define the model-implied disaster index on the real probability measure as

$$
\begin{aligned}
& {\left[(1-p) p\left(\mu-\mu_{J}\right)^{2}+(1-p) \sigma^{2}+p \sigma_{J}^{2}\right]-\sigma^{2}} \\
& =(1-p) p\left(\mu-\mu_{J}\right)^{2}+p\left(\sigma_{J}^{2}-\sigma^{2}\right)
\end{aligned}
$$

In Section 5, we calibrate the model and establish that the model-implied disaster index and $R N$ variance are very highly correlated with the expressions in equations (6) and (7), respectively.

A put option has strike $K$ and pays $[K-S]^{+}$units of the consumption good at the end of the period. Puts are in zero net supply. The put price at the beginning of the period is $P$. The put price must be lower than the strike price, $P \leq K$; otherwise a bond that pays K dominates the put.

There are two classes of price-taking agents, the "customer" and the "market maker". The customer has initial endowment $W_{0}$. He buys $\alpha$ shares of stock and $\beta$ puts, and invests $W_{0}-\alpha-\beta P$ units of the numeraire in bonds. He maximizes his expected quadratic utility:

$$
\max _{\alpha, \beta} E[U]
$$


where

$$
U \equiv W_{0}-\alpha-\beta P+\alpha S+\beta[K-S]^{+}-\frac{A}{2}\left(W_{0}-\alpha-\beta P+\alpha S+\beta[K-S]^{+}\right)^{2}
$$

and $A$ is a preference parameter. We specify the utility as quadratic merely for computational convenience. The customer's marginal utility is positive, provided $W_{0}-\alpha-\beta P+$ $\alpha S+\beta[K-S]^{+}<A^{-1}$. In our calibration, we set $W_{0} \ll A^{-1}$ and this guarantees that the marginal utility is positive. The relative risk aversion coefficient is $E\left[-\left(W_{0}-\alpha-\beta P+\right.\right.$ $\left.\left.\alpha S+\beta[K-S]^{+}\right) U^{\prime \prime} / U^{\prime}\right] \approx-W_{0} U^{\prime \prime} / U^{\prime}$. The objective function is concave in $\alpha$ and $\beta$. The first-order conditions are affine functions of $\alpha$ and $\beta$ and their optimal values are calculated in the appendix in closed form.

The market maker (MM) has zero endowment (without loss of generality), buys shares of stock and puts, and maximizes his expected payoff:

$$
\max _{\hat{\alpha}, \hat{\beta}} E\left[\hat{\alpha}(S-1)+\hat{\beta}\left([K-S]^{+}-P\right)\right]
$$

subject to an exogenous VaR constraint

$$
\operatorname{prob}\left\{\hat{\alpha}(S-1)+\hat{\beta}\left([K-S]^{+}-P\right)<W^{*}\right\} \leq h
$$

In equilibrium, the market maker writes puts. The constraint $\hat{\alpha} \leq 0$ captures the institutional role of a market maker that he may choose to hedge his position by selling stock short but does not speculate by buying stock. We model the market maker as risk neutral merely for convenience. What is important is that the market maker is less risk averse than the customer. In practice, market makers may or may not hedge their short positions in puts but this does not change the nature of our problem because the providers of the hedging 
instruments to the market makers also face credit constraints.

The equilibrium put price is such that the put market clears, $\beta+\hat{\beta}=0$. If the put price is lower than the expected payoff of a put, $P<E\left[[K-S]^{+}\right]$, the MM does not write puts and the supply of puts is zero. We calibrate the model in a way that the put price equals or exceeds the expected payoff of a put, $P \geq E\left[[K-S]^{+}\right]$. This captures the situation where the risk averse customer buys "overpriced" puts to hedge his investment in stock and the risk neutral MM writes these puts to maximize profit.

\section{Resolution of the Skew Response Puzzle}

We calibrate the model as follows. We set the length of the time period as one month. We set the range of $p$ as $0.04-0.16$, corresponding to $0.48-1.92$ expected disasters per year. This range of $p$ is in line with the estimates in Pan (2002), Eraker (2004), Eraker, Johannes, and Polson (2006), and Lian (2014). We set the range of $\sigma$ as 0.02 to 0.14 , which corresponds to the annual volatility ranging from 0.07 to 0.48 . We set $\mu=0.005$, corresponding to an annual equity premium with mean $6 \%$ in the no-disaster state; $\mu_{J}=-0.04$ and $\sigma_{J}=0.80 / \sqrt{12}$, corresponding to annual volatility $80 \%$ of the equity premium in the disaster state. For this range of parameters, the annual equity risk premium ranges from $2.86 \%$ to $17.04 \%$ and the annual volatility ranges from $7.38 \%$ to $45.01 \%$, consistent with the observed equity premium and volatility of the S\&P 500 index. We set the customer's initial wealth at $W_{0}=500$ and preference parameter at $A=0.001$. The customer's marginal utility is positive

since $500 \ll 0.001^{-1}$. The customer's relative risk aversion coefficient is approximately $-W_{0} U^{\prime \prime} / U^{\prime}=500 \times 0.001 /(1-500 \times 0.001)=1$, well within the range of the commonly assumed level of risk aversion. Finally, we set the market maker's initial wealth at zero, the VaR threshold at $W^{*}=-20$, and the VaR probability at $1 \%$. 
In figure 5, we display the supply and demand curves for ATM and OTM puts for and monthly disaster probability 0.05 or 0.10 . As the put price increases, the customer demands fewer puts and the market maker offers to write more puts although the supply is quite inelastic. When the volatility is 0.04 and the probability of disaster is 0.05 , the net buy of ATM puts is 101.44 and the net buy of OTM puts is 309.71 ; and when the volatility is 0.04 and the probability of disaster is 0.10 , the net buy of ATM puts is 74.36 and the net buy of OTM puts is 144.37.

[Figure 5 here]

We use a grid of parameter values $p=0.04,0.045, \ldots, 0.16$ and $\sigma=0.02,, 0.025, \ldots, 0.14$. For each parameter pair, we compute the cross-section of put prices with moneyness $(K / S)$ ranging from 0.8 to 1.15 . From each cross-section of put prices, we compute the disaster index, $R N$ variance, and the IV skew. The $R N$ variance has correlation 0.9998 with the model-implied variance in equation (6); and the disaster index has correlation 0.8841 with the model-implied disaster index in equation (7).

In figure 6 , we present the IV skew as a function of the disaster index and the $R N$ variance. In the first row, we fix as 0.04 or 0.08 and show that IV skew is increasing the disaster index. In the second row, we fix as 0.06 or 0.10 and show the IV skew is decreasing in the $R N$ variance.

\section{[Figure 6 here]}

In Table 1, we report regressions of the observed IV skew on the observed disaster index and $R N$ variance. We compute the standard errors as in Newey and West (1987) with 15 lags to correct for the autocorrelation of the IV skew. In univariate regressions, the coefficient of the disaster index is positive and most significant during the crisis period. The coefficient of 
the $R N$ variance is insignificant over the full period and subperiods, except during the crisis when it is positive and significant. We also report bi-variate regressions with both the $R N$ variance and disaster index as independent variables. For the whole period and subperiods, the IV skew is increasing in the disaster index and $R N$ variance but the coefficients are statistically significant only in the whole period and after the crisis. Overall, the results are ambiguous because of the high correlation between the disaster index and the $R N$ variance.

[Table 1 here]

As an alternative way to decompose the impact of the disaster index and $R N$ variance on the IV skew, we classify all the months over the time period January 1996-December 2012 into ten bins with equal number of months in each bin, based on increasing $R N$ variance. For each bin, we plot the IV skew as a function of disaster index and find a positive relationship, consistent with the model. In the first row of figure 7, we show these graphs for the second percentile of the $R N$ variance (low volatility risk) and the ninth percentile of the RN volatility (high volatility risk). Consistent with the model, the IV skew is increasing in the disaster index.

Next, we classify all months over the time period January 1996-December 2012 into ten bins with equal number of months in each bin, based on increasing disaster index. For each bin, we plot the IV skew as a function of the $R N$ variance and find a negative relationship, consistent with the model. In the second row of figure 7, we show these graphs for the second percentile of disaster index (low disaster risk) and the ninth percentile of disaster index (high disaster risk). Consistent with the model, the IV skew is decreasing in the $R N$ variance.

[Figure 7 here] 


\section{Model Implications on the Net Buy of Puts and Em- pirical Evidence}

In this section, we present several testable implications of the model regarding the net buy of puts. We find that the model implications regarding the relation between the net buy of puts and the disaster index, $R N$ variance, put price, and the IV skew are consistent with the empirical evidence. In none of the regressions presented in this section do we use variance, disaster risk, or index returns as control variables because the net buy of puts in our model is endogenous with these variables so that these variables cannot serve as control variables.

\subsection{The Net Buy of Puts versus the Disaster Index and $R N$ vari- ance}

We distinguish between a change in the net buy of OTM puts due to an increase in the disaster index and a change in the net buy of OTM puts due to an increase in the $R N$ variance. First, we fix $\sigma$ and vary $p$. For each value of $p$, we generate the cross-section of OTM put prices and calculate the disaster index. In the top row of figure 8 , we present the net buy of OTM puts as a function of the disaster index. The net buy is decreasing in the disaster index. Second, we fix $p$ and vary $\sigma$. For each value of $\sigma$, we generate the cross-section of OTM put prices and calculate the $R N$ variance. In the bottom row of figure 8 , we show that the net buy is decreasing in the $R N$ variance. Thus the model predicts that the net buy is decreasing in both the disaster index and the $R N$ variance. These results are consistent with our intuition. When the disaster index and/or the $R N$ variance increase, the customers like to buy more puts as insurance but the market makers become more creditconstrained. That is, both the supply and demand curves shift. The supply shift turns out 
to be the driving factor in the decrease in the equilibrium net buy of puts.

[Figure 8 here]

Corresponding results for ATM puts are presented in figure 9. The model implies that the net buy of ATM puts by customers is everywhere decreasing in the disaster index (top row of figure 9). The model also implies that the net buy of ATM puts is increasing in the $R N$ variance when the variance level is low and decreasing in the variance when the variance level is high (bottom row of figure 9).

[Figure 9 here]

In figure 10, we present the time series of the net buy by customers, the $R N$ variance, and the disaster index. Through most of the period January 1996 to December 2012, the net buy of OTM puts is mostly positive, with a slight negative net buy when the $R N$ variance and disaster risk are relatively high, such as around 1999 (dot-com bubble) and after the 2008 financial crisis. The net buy of OTM puts began rising in 2004 as the $R N$ variance and disaster index began to fall, consistent with our model. In 2007 right before the financial crisis, the net buy peaked. Since the financial crisis in 2008, the net buy of customers has started to decrease while the $R N$ variance and disaster index rose to unprecedented levels. This indicates that the market markets have gradually decreased their supply though the demand for OTM puts should be historically high. After the crisis, the net buy of OTM puts decreases to be negative in some months along with the high $R N$ variance and disaster index. The net buy of ATM puts is mostly positive throughout this period. The time-series pattern of ATM puts is similar as the pattern in the net buy of OTM puts. These patterns are consistent with the basic premise of our model, that customers buy puts as insurance while market makers write these puts. 
[Figure 10 here]

In Table 2, we report regressions of the monthly net buy of OTM puts by customers versus the disaster index and the $R N$ variance over the period 1996:1-2012:12. Here and throughout this section we compute the standard errors in all of the regressions as in Newey and West (1987) with 15 lags to correct for the autocorrelation of the net buy. Consistent with the model implications, in univariate regressions, the net buy is significantly decreasing in both the disaster index and the $R N$ variance in the full period and subperiods. We interpret the bivariate regressions with caution because of the high correlation between the disaster index and the $R N$ variance. In Table 3, we report the corresponding regressions for ATM puts. Again the results are consistent with the model implications. In univariate regressions, the net buy is significantly decreasing in both the disaster index and the $R N$ variance in the full period but the coefficients are insignificant in the subperiods.

[Tables 2 and 3 here]

\subsection{The Price of Puts versus the Net Buy of Puts}

The model implies that an increase in the put price positively shifts the supply and negatively shifts the demand for both OTM and ATM puts. In figure 11, we display the model-implied net buy of OTM puts as a function of the put price, where the put price is stated in terms of its Black-Scholes (B-S) implied volatility. We distinguish between an increase in the put price due to an increase in the $R N$ variance from an increase in the put price due to an increase in the disaster index. Keeping the $R N$ variance constant but varying the disaster risk, the net buy of OTM puts is decreasing the price of OTM puts (top row of figure 11 ). Keeping the disaster probability constant but varying the $R N$ variance, the net buy of OTM puts is decreasing in the price of OTM puts (bottom row of figure 11 ). Thus, our model 
implies that the net buy of OTM puts is decreasing in the price of OTM puts. Consistent with our model implications, the observed net buy of OTM puts is decreasing in the price of OTM puts (figure 12 ) for the full period and all the sub-periods.

[Figures 11 and 12 here]

In figure 13 we display the model-implied net buy of ATM puts as a function of the put price, expressed in terms of its B-S implied volatility. Keeping the variance constant but varying the disaster risk, the net buy of ATM puts is everywhere decreasing in the price of ATM puts (top row of figure 13). Keeping the disaster risk constant but varying the variance, the net buy of ATM puts is increasing in the price when the level of variance is low and decreasing in the price when the variance level is high (bottom row of figure 13). Thus, our model implies that the net buy of ATM puts may be either increasing or decreasing in the price of ATM puts. Our model implies that the decreasing pattern between the net buy and option prices is less significant for ATM puts than for OTM puts. Consistent with our model implications, the observed net buy of ATM puts is decreasing in the put price during the full sample period (figure 14). For the sub-periods, the plots do not show a clear relationship between the net buy and the price of ATM puts.

[Figures 13 and 14 here]

In the top panel of Table 4 , we report regressions of the net buy of OTM puts on the price of OTM puts. For the full period and the sub-periods, the regressions consistently show a significant negative relationship between the net buy and the price of OTM puts. In the bottom panel of Table 4 , we report regressions of the net buy of ATM puts on the price of ATM puts. For the full period and the sub-periods, the regressions consistently show a significant negative relationship between the net buy and the price of ATM puts. These regressions are consistent with the model implications. 
[Table 4 here]

\subsection{The IV Skew versus the Net Buy of Puts}

Consistent with our model implications, the observed IV skew shows no consistent pattern with the net buy of OTM and ATM puts. This contrasts with the implications of the model in Gârleanu et al. (2009) which assumes exogenous demand shifts and no supply shifts. Their Proposition 4 states that an exogenous positive shift in the demand for a certain OTM put has a bigger pricing effect on the demand of deep OTM puts than on slightly OTM puts, that is, the IV skew unambiguously becomes steeper.

As the disaster risk increases, keeping the $R N$ variance constant, the price of both the OTM and ATM puts increases. As we showed earlier in figure 6, the model implies that the price of OTM puts increases faster than the price of ATM puts and the IV skew becomes

steeper. Furthermore, as we showed earlier in figures 8 and 9, the model implies that the net buy of puts unambiguously decreases with the disaster index when the $R N$ variance is fixed. Therefore, the model predicts a negative relationship between the net buy and the IV skew when the disaster index increases. This is illustrated in the bottom row of figure 15 for OTM puts and the bottom row of figure 16 for ATM puts.

[Figures 15 and 16 here]

As the $R N$ variance increases, keeping the disaster index constant, the net buy of OTM puts and the IV skew is implied by our model as following. As we showed earlier in the bottom row of figure 6, the model implies that the price of OTM puts increases slower than the price of ATM puts and the IV skew becomes flatter. Furthermore, as we showed earlier in the bottom row of figure 8, the model implies that the net buy of OTM puts also decreases with the $R N$ variance. Therefore, whether the net buy increases or decreases with the IV 
skew depends on whether the skew or the net buy decreases faster with higher $R N$ variance. Our model predicts a positive relationship between the IV skew and the net buy of OTM puts when we increase the $R N$ variance. This is illustrated in the bottom row of figure 15 .

In contrast, as the $R N$ variance increases, keeping the disaster index constant, the relation between the net buy of ATM puts and the IV skew is implied by our model as following. as we showed earlier in the bottom row of figure 9, the model implies that the net buy of ATM puts increases with the $R N$ variance when the variance is relatively low and decreases with the $R N$ variance when the variance is relatively high. On the other hand, the IV skew always decreases with the $R N$ variance. Therefore, when the variance is relatively low, the skew is relatively high and meanwhile the skew is decreasing in the $R N$ variance. Therefore, our model implies that the net buy is decreasing in the IV skew when the IV skew is high. However, when the variance is relatively high, the IV skew is low and meanwhile both the net buy and the skew are decreasing in the variance risk. Therefore, the pattern of the net buy versus the skew again depends on which of the two decreases faster in the $R N$ variance. In the top row of figure 16, our model predicts that the net buy is decreasing in the IV skew when the IV skew is high and increasing in the IV skew when the IV skew is low.

Since the $R N$ variance and disaster index are highly correlated, our model is ambiguous regarding the relationship between the net buy and the IV skew of both OTM and ATM puts. These implications are consistent with the data. This is illustrated in figure 17 for OTM puts and figure 18 for ATM puts and the regressions in Table 5 . Note that in both figures 17 and 18 and Table 5, before, during, and after the crisis, the relationship between the net buy of OTM and ATM puts and the IV skew do not show a recognizable pattern.

[Table 5 and Figures 17 and 18 here]

The decreasing pattern between the skew and the net buy is most significant during the 
crisis and for OTM puts. This is the period when the net buy of puts was primarily driven by changes in the disaster probability rather than the $R N$ variance. During the financial crisis, the disaster risk is high and the market makers face a tighter constraint in terms of the VaR even if the variance risk is the same as in other sub-periods. This leads to a steeper the IV skew together with a less net buy of puts. Therefore, we observe a significant negative relationship between the IV skew and net buy of both OTM and ATM puts, though the pattern is more significant for OTM puts because of more demand in OTM puts as crash insurance.

\section{Concluding Remarks}

We document the skew response puzzle: no-arbitrage models imply that the IV skew is decreasing in the $R N$ variance and disaster index, contrary to the empirical evidence on S\&P 500 put options. We explain the puzzle by modeling the endogenous supply and demand of index puts. The key lies in recognizing that the principal suppliers of index puts are market makers who are subject to exogenous credit constraints. The model captures the scenario where risk neutral market makers write "overpriced" puts while the risk-averse public customers buy the index to maximize their utility and hedge their exposure to downside risk by buying index puts. The model implies that the IV skew is increasing in the disaster index and decreasing in the $R N$ variance. Since the $R N$ variance and disaster index is highly correlated, this leads to the observed non-decreasing IV skew in the $R N$ variance and disaster index.

The shift in the supply and demand for S\&P 500 put options not only explains the IV skew puzzle but also explains a novel set of empirical observations about the net buy of puts. The model and the data consistently imply that the net buy of puts is decreasing in the $R N$ 
variance and disaster index. The model and the data also consistently imply that the net buy of puts is decreasing in their price.

In our model, different months are associated with different parameter values. We make no assumptions about the time-series process of these parameters. In future research, it is of interest to model the time-series process of these parameters and study the time-series process of option prices and the net buy.

The paper focuses on OTM put options that derive their value from the left-hand tail of the index price distribution and give rise to a pronounced IV skew, unlike OTM call options that derive their value from the right-hand tail of the distribution and give rise to either a faint IV skew or a faint smirk. Constantinides, Czerwonko, Jackwerth, and Perrakis (2011) and Constantinides, Jackwerth, and Perrakis (2009) showed that OTM European calls on the S\&P 500 index and OTM American calls on the S\&P 500 index futures frequently imply stochastic dominance violations: any risk averse investor who invests in a portfolio of the index and the risk free asset increases his expected utility by writing OTM "overpriced" calls. Therefore, even the risk-averse customers have an incentive to write OTM calls. Our model does not capture the trading behavior of market makers and customers in OTM calls. We leave it as a project for future research to develop a model that captures the trading behavior of market makers and customers in OTM calls. 


\section{Appendix: The Customer's Problem}

For a given put price $P$, we numerically calculate the customer's optimal decisions $(\alpha, \beta)$ and the MM's optimal decisions $(\hat{\alpha}, \hat{\beta})$. Finally, we numerically search for the put price that satisfies the market clearing condition $\beta+\hat{\beta}=0$.

Before we compute the expectation in the customer's objective function, we compute the following:

$$
\begin{aligned}
& E\left[e^{\mu+\sigma Z}\right)=e^{\mu+\sigma^{2} / 2}=E_{1}(\mu, \sigma) \\
& E\left[\left(e^{\mu+\sigma Z}\right)^{2}\right)=e^{2 \mu+2 \sigma^{2}}=E_{2}(\mu, \sigma) \\
& \left.E\left[\left[K-e^{\mu+\sigma Z}\right]^{+}\right]=\int_{-\infty}^{+\infty}\left(K-e^{\tau}\right)^{+} f(\tau) d \tau=K \int_{-\infty}^{\log (K)} f(\tau) d \tau-\int_{-\infty}^{\log (K)} e^{\tau} f(\tau) d\right] \tau \\
& =K \Phi\left(\frac{\log (K)-\mu}{\sigma}\right)-e^{\mu+\sigma^{2} / 2} \Phi\left(\frac{\log (K)-\mu-\sigma^{2}}{\sigma}\right) \\
& =F_{1}(\mu, \sigma ; K) \\
& E\left[\left(\left(K-e^{\mu+\sigma Z}\right)^{+}\right)^{2}\right]=\int_{-\infty}^{+\infty}\left(\left(K-e^{\tau}\right)^{+}\right)^{2} f(\tau) d \tau=\int_{-\infty}^{\log (K)}\left(K^{2}-2 K e^{\tau}+e^{2 \tau}\right) f(\tau) d \tau \\
& =K^{2} \int_{-\infty}^{\log (K)} f(\tau) d \tau-2 K \int_{-\infty}^{\log (K)} e^{\tau} f(\tau) d \tau+\int_{-\infty}^{K} e^{2 \tau} f(\tau) d \tau \\
& =K^{2} \Phi\left(\frac{\log (K)-\mu}{\sigma}\right)-2 K e^{\mu+\sigma^{2} / 2} \Phi\left(\frac{\log (K)-\mu-\sigma^{2}}{\sigma}\right) \\
& +e^{2 \mu+2 \sigma^{2}} \Phi\left(\frac{\log (K)-\mu-2 \sigma^{2}}{y}\right) \\
& =F_{2}(\mu, \sigma ; K) \\
& E\left[e^{\mu+\sigma Z}\left(K-e^{\mu+\sigma Z}\right)^{+}\right]=\int_{-\infty}^{+\infty} e^{\tau}\left(K-e^{\tau}\right)^{+} f(\tau) d \tau=K \int_{-\infty}^{\log (K)} e^{\tau} f(\tau) d \tau-\int_{-\infty}^{\log (K)} e^{2 \tau} f(\tau) d \tau \\
& =K e^{\mu+\sigma^{2} / 2} \Phi\left(\frac{\log (K)-\mu-\sigma^{2}}{\sigma}\right)-e^{2 \mu+2 \sigma^{2}} \Phi\left(\frac{\log (K)-\mu-2 \sigma^{2}}{y}\right) \\
& =F_{3}(\mu, \sigma ; K)
\end{aligned}
$$

where $f(\cdot)$ is the density function and $\Phi(\cdot)$ is the CDF of the standard normal distribution. 
We write the objective function of the customer as

$$
\max _{\alpha, \beta}\left[\begin{array}{l}
\alpha(1-p)\left(1-A W_{0}\right)\left[E_{1}(\mu, \sigma)-1\right]+\beta(1-p)\left(1-A W_{0}\right)\left[F_{1}(\mu, \sigma ; K)-P\right] \\
-\alpha^{2} \frac{A}{2}(1-p)\left[E_{2}(\mu, \sigma)-2 E_{1}(\mu, \sigma)+1\right]+\alpha \beta A(1-p)\left[F_{1}(\mu, \sigma ; K)\right. \\
\left.-F_{3}(\mu, \sigma ; K)+P E_{1}(\mu, \sigma)-P\right]-\beta^{2} \frac{A}{2}(1-p)\left[F_{2}(\mu, \sigma ; K)\right. \\
\left.-2 P F_{1}(\mu, \sigma ; K)+P^{2}\right]+\alpha p\left(1-A W_{0}\right)\left[E_{1}\left(\mu_{J}, \sigma_{J}\right)-1\right] \\
+\beta p\left(1-A W_{0}\right)\left[F_{1}\left(\mu_{J}, \sigma_{J} ; K\right)-P\right] \\
-\alpha^{2} \frac{A}{2} p\left[E_{2}\left(\mu_{J}, \sigma_{J}\right)-2 E_{1}\left(\mu_{J}, \sigma_{J}\right)+1\right]+\alpha \beta A p\left[F_{1}\left(\mu_{J}, \sigma_{J} ; K\right)\right. \\
\left.-F_{3}\left(\mu_{J}, \sigma_{J} ; K\right)+P E_{1}\left(\mu_{J}, \sigma_{J}\right)-P\right]-\beta^{2} \frac{A p}{2}\left[F_{2}\left(\mu_{J}, \sigma_{J} ; K\right)\right. \\
\left.-2 P F_{1}\left(\mu_{J}, \sigma_{J} ; K\right)+P^{2}\right]
\end{array}\right]
$$

The first-order conditions are:

$$
\begin{aligned}
& (1-p)\left(1-A W_{0}\right)\left[E_{1}(\mu, \sigma)-1\right]-\alpha A(1-p)\left[E_{2}(\mu, \sigma)-2 E_{1}(\mu, \sigma)+1\right] \\
& +\beta A(1-p)\left[F_{1}(\mu, \sigma ; K)-F_{3}(\mu, \sigma ; K)+P E_{1}(\mu, \sigma)-P\right] \\
& +p\left(1-A W_{0}\right)\left[E_{1}\left(\mu_{J}, \sigma_{J}\right)-1\right]-\alpha A p\left[E_{2}\left(\mu_{J}, \sigma_{J}\right)-2 E_{1}\left(\mu_{J}, \sigma_{J}\right)+1\right] \\
& +\beta A p\left[F_{1}\left(\mu_{J}, \sigma_{J} ; K\right)-F_{3}\left(\mu_{J}, \sigma_{J} ; K\right)+P E_{1}\left(\mu_{J}, \sigma_{J}\right)-P\right] \\
& =0 \\
& (1-p)\left(1-A W_{0}\right)\left[F_{1}(\mu, \sigma ; K)-P\right]+\alpha A(1-p)\left[F_{1}(\mu, \sigma ; K)-F_{3}(\mu, \sigma ; K)\right. \\
& \left.+P E_{1}(\mu, \sigma)-P\right]-\beta A(1-p)\left[F_{2}(\mu, \sigma ; K)-2 P F_{1}(\mu, \sigma ; K)+P^{2}\right] \\
& +p\left(1-A W_{0}\right)\left[F_{1}\left(\mu_{J}, \sigma_{J} ; K\right)-P\right]+\alpha A p\left[F_{1}\left(\mu_{J}, \sigma_{J} ; K\right)-F_{3}\left(\mu_{J}, \sigma_{J} ; K\right)\right. \\
& \left.+P E_{1}\left(\mu_{J}, \sigma_{J}\right)-P\right]-\beta A p\left[F_{2}\left(\mu_{J}, \sigma_{J} ; K\right)-2 P F_{1}\left(\mu_{J}, \sigma_{J} ; K\right)+P^{2}\right] \\
& =0
\end{aligned}
$$


with solution

$$
\left(\begin{array}{l}
\alpha \\
\beta
\end{array}\right)=\left(\begin{array}{ll}
a_{11} & a_{12} \\
a_{21} & a_{22}
\end{array}\right)^{-1}\left(\begin{array}{l}
c_{1} \\
c_{2}
\end{array}\right)
$$

where,

$$
\begin{aligned}
a_{11}= & A(1-p)\left[E_{2}(\mu, \sigma)-2 E_{1}(\mu, \sigma)+1\right]+A p\left[E_{2}\left(\mu_{J}, \sigma_{J}\right)-2 E_{1}\left(\mu_{J}, \sigma_{J}\right)+1\right] \\
a_{12}= & A(1-p)\left[-F_{1}(\mu, \sigma ; K)+F_{3}(\mu, \sigma ; K)-P E_{1}(\mu, \sigma)+P\right]+A p\left[-F_{1}\left(\mu_{J}, \sigma_{J} ; K\right)\right. \\
& \left.+F_{3}\left(\mu_{J}, \sigma_{J} ; K\right)-P E_{1}\left(\mu_{J}, \sigma_{J}\right)+P\right] \\
a_{21}= & A(1-p)\left[-F_{1}(\mu, \sigma ; K)+F_{3}(\mu, \sigma ; K)-P E_{1}(\mu, \sigma)+P\right]+A p\left[-F_{1}\left(\mu_{J}, \sigma_{J} ; K\right)\right. \\
& \left.+F_{3}\left(\mu_{J}, \sigma_{J} ; K\right)-P E_{1}\left(\mu_{J}, \sigma_{J}\right)+P\right] \\
a_{22}= & -A(1-p)\left[F_{2}(\mu, \sigma ; K)-2 P F_{1}(\mu, \sigma ; K)+P^{2}\right]-A p\left[F_{2}\left(\mu_{J}, \sigma_{J} ; K\right)\right. \\
& \left.-2 P F_{1}\left(\mu_{J}, \sigma_{J} ; K\right)+P^{2}\right] \\
c_{1}= & (1-p)\left(1-A W_{0}\right)\left[E_{1}(\mu, \sigma)-1\right]+p\left(1-A W_{0}\right)\left[E_{1}\left(\mu_{J}, \sigma_{J}\right)-1\right] \\
c_{2}= & (1-p)\left(1-A W_{0}\right)\left[F_{1}(\mu, \sigma ; K)-P\right]+p\left(1-A W_{0}\right)\left[F_{1}\left(\mu_{J}, \sigma_{J} ; K\right)-P\right]
\end{aligned}
$$




\section{References}

[1] Adrian, T. and H. S. Shin. 2014. Procyclical Leverage and Value-at-Risk. Review of Financial Studies 2\%: 373-403.

[2] Andersen, T. G., L. Benzoni, and J. Lund. 2002. An Empirical Investigation of Continuous-Time Equity Return Models. The Journal of Finance 5\%: 1239-1284.

[3] Andersen, T.G., N. Fusari, and V. Todorov. 2015a. Parametric Inference and Dynamic State Recovery from Option Panels. Econometrica, forthcoming.

[4] Andersen, T.G., N. Fusari, and V. Todorov. 2015b. The Risk Premia Embedded in Index Options. Journal of Financial Economics, forthcoming.

[5] Bakshi, G., C. Cao, and Z. Chen. 1997. Empirical Performance of Alternative Option Pricing Models. The Journal of Finance 52: 2003-2049.

[6] Bakshi, G., N. Kapadia, and D. Madan. 2003. Stock Return Characteristics, Skew Laws, and the Differential Pricing of Individual Equity Options. Review of Financial Studies 18: 101-143.

[7] Bates, D. S. 2000. Post-87' Crash Fears in the S\&P 500 Futures Options Market. Journal of Econometrics 94: 181-238.

[8] Bates, D. S. 2003. Empirical Option Pricing: A Retrospection. Journal of Econometrics 116: 387-404.

[9] Bates, D. S. 2006. Maximum Likelihood Estimation of Latent Affine Processes. Review of Financial Studies 19: 909-965.

[10] Black, F. and M. Scholes. 1973. The Pricing of Options and Corporate Liabilities. Journal of Political Economy 81: 637-654. 
[11] Bollen, N. P. B. and R. E. Whaley. 2004. Does Net Buying Pressure Affect the Shape of Implied Volatility Functions? The Journal of Finance 59: 711-753.

[12] Britten-Jones, M. and A. Neuberger. 2000. Option Prices, Implied Price Processes, and Stochastic Volatility. The Journal of Finance 55: 839-866.

[13] Broadie, M., M. Chernov, and M. Johannes. 2007. Model Specification and Risk Premia: Evidence from Futures Options. The Journal of Finance 62: 1453-1490.

[14] Brunnermeier, M. K. and L. H. Pedersen. 2009. Market Liquidity and Funding Liquidity. Review of Financial Studies 22: 2201-2238.

[15] Buraschi, A. and J. C. Jackwerth. 2001. The Price of a Smile: Hedging and Spanning in Option Markets. Review of Financial Studies 14: 495-527.

[16] Cao, C. and J. Huang. 2008. Determinants of S\&P 500 Index Option Returns. Review of Derivatives Research 10: 1-38.

[17] Carverhill, A. P., S. Dyrting, and T. H. F. Cheuk. 2009 Futures Options: A Linearized Factor Analysis. Review of Derivatives Research 12: 109-139.

[18] Chen, H., S. Joslin, and S. Ni. 2013. Demand for Crash Insurance, Intermediary Constraints, and Stock Return Predictability. Working paper, MIT and NBER.

[19] Chernov, M., A. R. Gallant, E. Ghysels, and G. Tauchen. 2003. Alternative Models for Stock Price Dynamics, Journal of Econometrics 116: 225-257.

[20] Constantinides, G. M., M. Czerwonko, J. C. Jackwerth, and S. Perrakis. 2011. Are Options on Index Futures Profitable for Risk Averse Investors? Empirical Evidence. The Journal of Finance 66: 1407-1437.

[21] Constantinides, G. M., C. Jackwerth, and S. Perrakis. 2009. Mispricing of S\&P 500 Index Options. Review of Financial Studies 22: 1247-1277. 
[22] Constantinides, G. M., J. C. Jackwerth, and A. Z. Savov. 2013. The Puzzle of Index Option Returns. Review of Asset Pricing Studies 3: 229-257.

[23] Danielsson, J., H. S. Shin, and J-P. Zigrand. 2004. The Impact of Risk Regulation on Price Dynamics. Journal of Banking and Finance 28: 1069-1087.

[24] Du, J. and N. Kapadia. 2012. Tail and Volatility Indices from Option Prices. Working paper, University of Massachusetts at Amherst.

[25] Duffie, D., J. Pan, and K. Singleton. 2000. Transform Analysis and Asset Pricing for Affine Jump-Diffusions. Econometrica 68: 1343-1376.

[26] Eraker, B. 2004. Do Stock Prices and Volatility Jump? Reconciling Evidence from Spot and Option Prices. The Journal of Finance 59: 1367-1403.

[27] Gârleanu, N., L. H. Pedersen, and A. M. Poteshman. 2009. Demand-Based Option Pricing. Review of Financial Studies 22: 4259-4299.

[28] Gromb, D. and D. Vayanos. 2002. Equilibrium and Welfare in Markets with Financially Constrained Arbitrageurs. Journal of Financial Economics 66: 361-407.

[29] He, Z. and A. Krishnamurthy. 2013. Intermediary Asset Pricing. American Economic Review 103: 732-770.

[30] Heston, S. L. 1993. A Closed-Form Solution for Options with Stochastic Volatility with Applications to Bond and Currency Options. Review of Financial Studies 6: 327-343.

[31] Heston, S. L., P. Christoffersen, and K. Jacobs. 2009. The Shape and Term Structure of the Volatility Smirk. Management Science 55: 1914-1932.

[32] Hu, G. X., J. Pan, and J. Wang. 2013. Noise as Information for Illiquidity. The Journal of Finance 68: 2341-2382. 
[33] Jones, C. S. 2006. A Nonlinear Factor Analysis of S\&P 500 Index Options Returns. The Journal of Finance 61: 2325-2363.

[34] Lian, L. 2014. The Role of Volatility Jumps in the Cross-Section of Option Prices. Working paper, University of Massachusetts at Amherst.

[35] Merton, R. C. 1973. Theory of Rational Option Pricing. Bell Journal of Economics and Management Science 4: 141-183.

[36] Pan, J., 2002. The Jump-Risk Premia Implicit in Options: Evidence from an Integrated Time-Series Study. Journal of Financial Economics 63: 3-50.

[37] Shleifer, A. and R. Vishny. 1997. The Limits of Arbitrage. The Journal of Finance 52: $35-55$.

[38] Thurner, J., D. Farmer, and J. Gaenakoplos. 2012. Leverage Causes Fat Tails and Clustered Volatility. Quantitative Finance 5: 695-707. 
Table 1: The Empirical IV Slope versus the Empirical VIX and Disaster Risk, Annual Data, 1996:1-2012:12

The table reports regressions of the IV skew on the disaster index and $R N$ variance for the full sample period, before the crisis, during the crisis, and after the crisis. The variables are defined in Section 2.The OTM puts are S\&P 500 puts with moneyness 0.80 - 0.90 and maturity 15 - 60 days. The ATM puts are S\&P 500 puts with moneyness $0.97-1.03$ and maturity 15 - 60 days.

\begin{tabular}{|c|c|c|c|c|c|c|}
\hline & \multicolumn{3}{|c|}{ Full Period } & \multicolumn{3}{|c|}{ Before Crisis } \\
\hline Disaster & 1.152 & & $11.40^{* *}$ & $3.603^{*}$ & & 10.24 \\
\hline Index & $(0.967)$ & & $(3.668)$ & $(1.556)$ & & $(5.294)$ \\
\hline $\mathrm{RN}$ & & 0.0104 & $-0.706^{* *}$ & & 0.0707 & -0.493 \\
\hline Variance & & $(0.0386)$ & $(0.227)$ & & $(0.136)$ & $(0.276)$ \\
\hline \multirow[t]{2}{*}{ constant } & $0.118^{* * *}$ & $0.120^{* * *}$ & $0.134^{* * *}$ & $0.110^{* * *}$ & $0.112^{* * *}$ & $0.122^{* * *}$ \\
\hline & $(0.00458)$ & $(0.00515)$ & $(0.00725)$ & $(0.00440)$ & $(0.00727)$ & $(0.00699)$ \\
\hline$N$ & 204 & 204 & 204 & 143 & 143 & 143 \\
\hline \multirow[t]{2}{*}{$\operatorname{adj} . R^{2}$} & 0.022 & -0.004 & 0.224 & 0.096 & 0.003 & 0.212 \\
\hline & \multicolumn{3}{|c|}{ During Crisis } & \multicolumn{3}{|c|}{ After Crisis } \\
\hline Disaster & $1.103^{* * *}$ & & 1.675 & 1.029 & & $25.21^{* * *}$ \\
\hline Index & $(0.227)$ & & (1.196) & $(0.906)$ & & $(1.543)$ \\
\hline$[1 \mathrm{em}] \mathrm{RN}$ & & $0.0757^{* * *}$ & -0.0407 & & -0.0262 & $-1.680^{* * *}$ \\
\hline Variance & & $(0.0160)$ & $(0.0892)$ & & $(0.0420)$ & $(0.0882)$ \\
\hline constant & $0.0988^{* * *}$ & $0.0962^{* * *}$ & $0.100^{* * *}$ & $0.140^{* * *}$ & $0.144^{* * *}$ & $0.169^{* * *}$ \\
\hline & $(0.00467)$ & $(0.00515)$ & $(0.00783)$ & $(0.00283)$ & $(0.00234)$ & $(0.00194)$ \\
\hline$N$ & 19 & 19 & 19 & 204 & 204 & 204 \\
\hline $\operatorname{adj} . R^{2}$ & 0.281 & 0.265 & 0.238 & 0.022 & -0.004 & 0.224 \\
\hline
\end{tabular}

Standard errors in parentheses

${ }^{*} p<0.05,{ }^{* *} p<0.01,{ }^{* * *} p<0.001$ 
Table 2: Observed Net Buy of OTM Puts versus the Disaster Index and the $R N$ variance

The table reports regressions of the net buy of OTM puts on the disaster index and $R N$ variance for the full sample period, before the crisis, during the crisis, and after the crisis. The variables are defined in Section 2.The OTM puts are S\&P 500 puts with moneyness 0.80 - 0.90 and maturity 15 - 60 days.

\begin{tabular}{|c|c|c|c|c|c|c|}
\hline & \multicolumn{3}{|c|}{ Full Period } & \multicolumn{3}{|c|}{ Before Crisis } \\
\hline $\begin{array}{l}\text { Disaster } \\
\text { Index }\end{array}$ & $\begin{array}{l}-3.436^{*} \\
(1.422)\end{array}$ & & $\begin{array}{l}3.469^{*} \\
(1.388)\end{array}$ & $\begin{array}{l}-6.997^{*} \\
(3.205)\end{array}$ & & $\begin{array}{c}1.908 \\
(1.109)\end{array}$ \\
\hline $\begin{array}{l}\mathrm{RN} \\
\text { Variance }\end{array}$ & & $\begin{array}{c}-0.196^{* * *} \\
(0.0583)\end{array}$ & $\begin{array}{c}-0.315^{* * *} \\
(0.0712)\end{array}$ & & $\begin{array}{c}-0.302^{* * *} \\
(0.0527)\end{array}$ & $\begin{array}{c}-0.345^{* * *} \\
(0.0661)\end{array}$ \\
\hline constant & $\begin{array}{c}0.0261^{* * *} \\
(0.00581)\end{array}$ & $\begin{array}{c}0.0608^{* * *} \\
(0.0130)\end{array}$ & $\begin{array}{c}0.0792^{* * *} \\
(0.0140)\end{array}$ & $\begin{array}{c}0.0350^{* * *} \\
(0.00819)\end{array}$ & $\begin{array}{c}0.0851^{* * *} \\
(0.0112)\end{array}$ & $\begin{array}{c}0.0907^{* * *} \\
(0.0125)\end{array}$ \\
\hline $\begin{array}{l}N \\
\text { adj. } R^{2}\end{array}$ & $\begin{array}{c}204 \\
0.081\end{array}$ & $\begin{array}{c}204 \\
0.172\end{array}$ & $\begin{array}{c}204 \\
0.190\end{array}$ & $\begin{array}{c}143 \\
0.099\end{array}$ & $\begin{array}{c}143 \\
0.223\end{array}$ & $\begin{array}{c}143 \\
0.221\end{array}$ \\
\hline & \multicolumn{3}{|c|}{ During Crisis } & \multicolumn{3}{|c|}{ After Crisis } \\
\hline $\begin{array}{l}\text { Disaster } \\
\text { Index }\end{array}$ & $\begin{array}{c}-1.466^{* * *} \\
(0.154)\end{array}$ & & $\begin{array}{c}1.226 \\
(1.063)\end{array}$ & $\begin{array}{c}-5.916^{* * *} \\
(1.310)\end{array}$ & & $\begin{array}{l}-2.283 \\
(2.380)\end{array}$ \\
\hline $\begin{array}{l}\mathrm{RN} \\
\text { Variance }\end{array}$ & & $\begin{array}{c}-0.0902^{* * *} \\
(0.00909)\end{array}$ & $\begin{array}{l}-0.156^{*} \\
(0.0639)\end{array}$ & & $\begin{array}{c}-0.203^{* * *} \\
(0.0449)\end{array}$ & $\begin{array}{c}-0.130 \\
(0.0915)\end{array}$ \\
\hline constant & $\begin{array}{l}0.0202^{* * *} \\
(0.00292) \\
\end{array}$ & $\begin{array}{c}0.0406^{* * *} \\
(0.00416)\end{array}$ & $\begin{array}{c}0.0545^{* *} \\
(0.0144) \\
\end{array}$ & $\begin{array}{c}0.0150^{* * *} \\
(0.00273)\end{array}$ & $\begin{array}{l}0.0453^{* * *} \\
(0.00863)\end{array}$ & $\begin{array}{l}0.0348^{*} \\
(0.0140)\end{array}$ \\
\hline $\begin{array}{l}N \\
\text { adj. } R^{2}\end{array}$ & $\begin{array}{c}19 \\
0.120\end{array}$ & $\begin{array}{c}19 \\
0.160\end{array}$ & $\begin{array}{c}19 \\
0.117\end{array}$ & $\begin{array}{c}42 \\
0.160\end{array}$ & $\begin{array}{c}42 \\
0.166\end{array}$ & $\begin{array}{c}42 \\
0.147\end{array}$ \\
\hline
\end{tabular}

Standard errors in parentheses

${ }^{*} p<0.05,{ }^{* *} p<0.01,{ }^{* * *} p<0.001$ 
Table 3: Observed Net Buy of ATM Puts versus the Disaster Index and the $R N$ variance

The table reports regressions of the net buy of ATM puts on the disaster index and $R N$ variance for the full sample period, before the crisis, during the crisis, and after the crisis. The variables are defined in Section 2.The ATM puts are S\&P 500 puts with moneyness 0.80 - 0.90 and maturity 15 - 60 days.

\begin{tabular}{|c|c|c|c|c|c|c|}
\hline & \multicolumn{3}{|c|}{ Full Period } & \multicolumn{3}{|c|}{ Before Crisis } \\
\hline $\begin{array}{l}\text { Disaster } \\
\text { Index }\end{array}$ & $\begin{array}{l}-2.724^{*} \\
(1.119)\end{array}$ & & $\begin{array}{l}-3.677 \\
(2.493)\end{array}$ & $\begin{array}{l}-1.425 \\
(4.421)\end{array}$ & & $\begin{array}{l}-5.553 \\
(4.364)\end{array}$ \\
\hline $\begin{array}{l}\mathrm{RN} \\
\text { Variance }\end{array}$ & & $\begin{array}{c}-0.0830 \\
(0.0623)\end{array}$ & $\begin{array}{l}0.0435 \\
(0.113)\end{array}$ & & $\begin{array}{c}0.0368 \\
(0.113)\end{array}$ & $\begin{array}{c}0.160 \\
(0.128)\end{array}$ \\
\hline constant & $\begin{array}{l}0.0494^{* * *} \\
(0.00569)\end{array}$ & $\begin{array}{c}0.0616^{* * *} \\
(0.0136)\end{array}$ & $\begin{array}{c}0.0420^{*} \\
(0.0186)\end{array}$ & $\begin{array}{l}0.0536^{* * *} \\
(0.00831)\end{array}$ & $\begin{array}{c}0.0443 \\
(0.0225)\end{array}$ & $\begin{array}{c}0.0278 \\
(0.0222)\end{array}$ \\
\hline $\begin{array}{l}N \\
\text { adj. } R^{2}\end{array}$ & $\begin{array}{c}204 \\
0.034\end{array}$ & $\begin{array}{c}204 \\
0.018\end{array}$ & $\begin{array}{c}204 \\
0.030\end{array}$ & $\begin{array}{c}143 \\
-0.004\end{array}$ & $\begin{array}{c}143 \\
-0.005\end{array}$ & $\begin{array}{c}143 \\
0.008\end{array}$ \\
\hline & \multicolumn{3}{|c|}{ During Crisis } & \multicolumn{3}{|c|}{ After Crisis } \\
\hline $\begin{array}{l}\text { Disaster } \\
\text { Index }\end{array}$ & $\begin{array}{c}-1.086^{* * *} \\
(0.180)\end{array}$ & & $\begin{array}{l}1.927^{*} \\
(0.761)\end{array}$ & $\begin{array}{l}-0.296 \\
(1.097)\end{array}$ & & $\begin{array}{l}13.39^{* *} \\
(4.528)\end{array}$ \\
\hline $\begin{array}{l}\mathrm{RN} \\
\text { Variance }\end{array}$ & & $\begin{array}{c}-0.0713^{* * *} \\
(0.0111)\end{array}$ & $\begin{array}{c}-0.174^{* *} \\
(0.0488)\end{array}$ & & $\begin{array}{l}-0.0629 \\
(0.0605)\end{array}$ & $\begin{array}{c}-0.490^{*} \\
(0.186)\end{array}$ \\
\hline constant & $\begin{array}{l}0.0155^{* * *} \\
(0.00240)\end{array}$ & $\begin{array}{l}0.0321^{* * *} \\
(0.00443)\end{array}$ & $\begin{array}{c}0.0538^{* * *} \\
(0.0116)\end{array}$ & $\begin{array}{l}0.0341^{* * *} \\
(0.00406)\end{array}$ & $\begin{array}{c}0.0468^{* * *} \\
(0.0112)\end{array}$ & $\begin{array}{l}0.108^{* * *} \\
(0.0295)\end{array}$ \\
\hline $\begin{array}{l}N \\
\text { adj. } R^{2}\end{array}$ & $\begin{array}{c}19 \\
0.059\end{array}$ & $\begin{array}{c}19 \\
0.105\end{array}$ & $\begin{array}{c}19 \\
0.079\end{array}$ & $\begin{array}{c}42 \\
-0.025\end{array}$ & $\begin{array}{c}42 \\
-0.006\end{array}$ & $\begin{array}{c}42 \\
0.076\end{array}$ \\
\hline
\end{tabular}


Table 4: Observed Net Buy of OTM and ATM Puts versus the Put Price in IV Units

The table reports regressions of the net buy of OTM and ATM puts for the full period and sub-periods on the disaster index and $R N$ variance. Full sample period: 01/1996-12/2012; before crisis: 01/1996-11/2007; during crisis: 12/2007-06/2009; after crisis: 07/2009-12/2012. The variables are defined in Section 2. The OTM puts are S\&P 500 puts with moneyness 0.80 - 0.90 and maturity 15 - 60 days. The ATM puts are S\&P 500 puts with moneyness $0.97-1.03$ and maturity 15 - 60 days.

\begin{tabular}{lcccc}
\hline \hline & \multicolumn{4}{c}{ Net Buys of OTM Puts } \\
\hline B-S IV (OTM) & $-0.211^{* * *}$ & $-0.296^{* * *}$ & $-0.0927^{* * *}$ & $-0.233^{* * *}$ \\
& $(0.0604)$ & $(0.0611)$ & $(0.00954)$ & $(0.0526)$ \\
& & & & \\
constant & $0.0848^{* * *}$ & $0.112^{* * *}$ & $0.0492^{* * *}$ & $0.0786^{* * *}$ \\
& $(0.0193)$ & $(0.0195)$ & $(0.00505)$ & $(0.0163)$ \\
\hline$N$ & 204 & 143 & 19 & 42 \\
adj. $R^{2}$ & 0.186 & 0.203 & 0.165 & 0.181 \\
\hline \multicolumn{5}{c}{ Net Buys of ATM Puts } \\
\hline B-S IV (ATM) & Full Period & Before Crisis & During Crisis & After Crisis \\
\hline & $-0.0893^{*}$ & 0.0406 & $-0.0791^{*}$ & -0.0721 \\
constant & $(0.0360)$ & $(0.0667)$ & $(0.0369)$ & $(0.0930)$ \\
& $0.0610^{* * *}$ & $0.0444^{* * *}$ & $0.0329^{* *}$ & $0.0469^{*}$ \\
$N$ & $(0.00754)$ & $(0.0120)$ & $(0.0106)$ & $(0.0182)$ \\
\hline adj. $R^{2}$ & 204 & 143 & 19 & 42 \\
\hline \hline Stang & 0.018 & -0.005 & 0.113 & -0.004 \\
\hline
\end{tabular}

Standard errors in parentheses

${ }^{*} p<0.05,{ }^{* *} p<0.01,{ }^{* * *} p<0.001$ 
Table 5: Observed Net Buy of OTM and ATM Puts versus IV Skew

The table reports regressions of the net buy of OTM and ATM puts for the full period and sub-periods on the IV skew. Full sample period: 01/1996-12/2012; before crisis: 01/1996-11/2007; during crisis: 12/200706/2009; after crisis: 07/2009-12/2012. The variables are defined in Section 2.The OTM puts are S\&P 500 puts with moneyness 0.80 - 0.90 and maturity 15 - 60 days. The ATM puts are S\&P 500 puts with moneyness $0.97-1.03$ and maturity $15-60$ days.

\begin{tabular}{|c|c|c|c|c|}
\hline & \multicolumn{4}{|c|}{ OTM Puts } \\
\hline & Full Period & Before Crisis & During Crisis & After Crisis \\
\hline \multirow[t]{2}{*}{ IV Skew } & -0.233 & -0.0148 & $-0.623^{*}$ & $-0.234^{*}$ \\
\hline & $(0.139)$ & $(0.238)$ & $(0.223)$ & $(0.112)$ \\
\hline \multirow[t]{2}{*}{ constant } & $0.0470^{* *}$ & 0.0269 & $0.0768^{* *}$ & $0.0354^{*}$ \\
\hline & $(0.0160)$ & $(0.0250)$ & $(0.0240)$ & $(0.0174)$ \\
\hline$N$ & 204 & 143 & 19 & 42 \\
\hline \multirow[t]{3}{*}{ adj. $R^{2}$} & 0.014 & -0.007 & 0.063 & -0.010 \\
\hline & \multicolumn{4}{|c|}{ ATM Puts } \\
\hline & Full Period & Before Crisis & During Crisis & After Crisis \\
\hline \multirow[t]{2}{*}{ IV Skew } & -0.101 & -0.103 & -0.0246 & 0.235 \\
\hline & $(0.199)$ & $(0.257)$ & $(0.209)$ & $(0.327)$ \\
\hline \multirow[t]{2}{*}{ constant } & $0.0560^{*}$ & $0.0635^{*}$ & 0.0113 & -0.0000772 \\
\hline & $(0.0254)$ & $(0.0279)$ & $(0.0233)$ & $(0.0476)$ \\
\hline$N$ & 204 & 143 & 19 & 42 \\
\hline $\operatorname{adj} . R^{2}$ & -0.002 & -0.005 & -0.059 & -0.010 \\
\hline
\end{tabular}


Figure 1: The IV Skew versus the $R N$ variance and Disaster Index Implied by the Bates (2006) No-Arbitrage Model
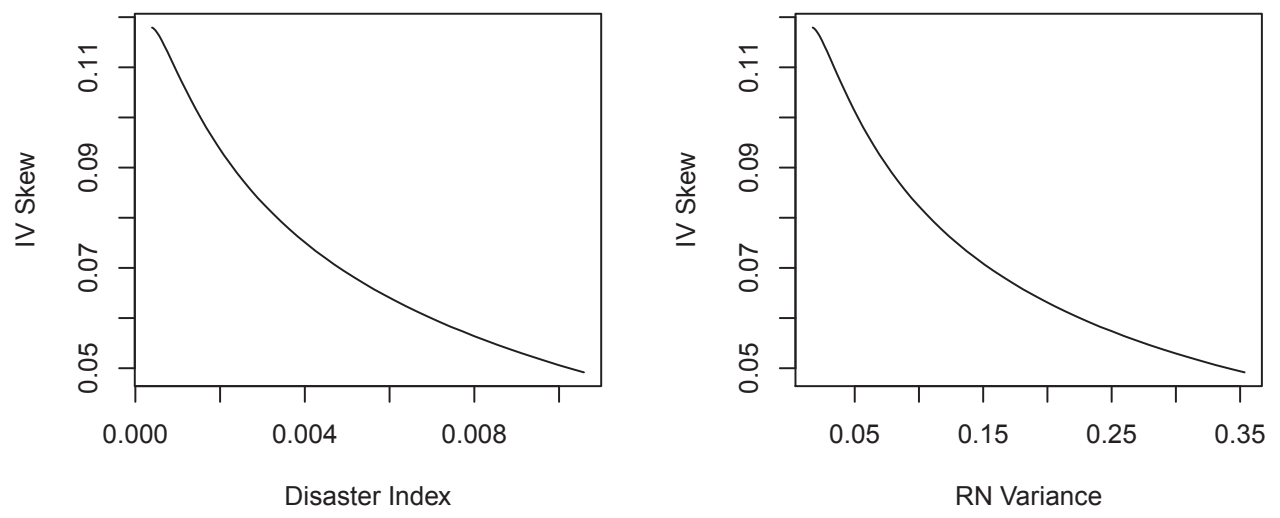

Figure 2: Observed Disaster Index versus Risk Neutral Variance

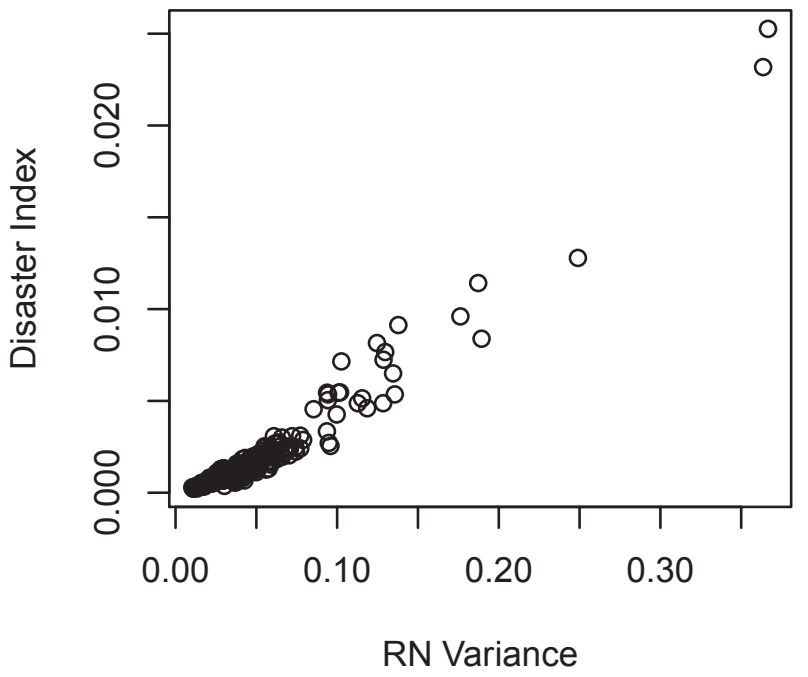


Figure 3: Observed IV Skew versus the $R N$ variance and Disaster Index
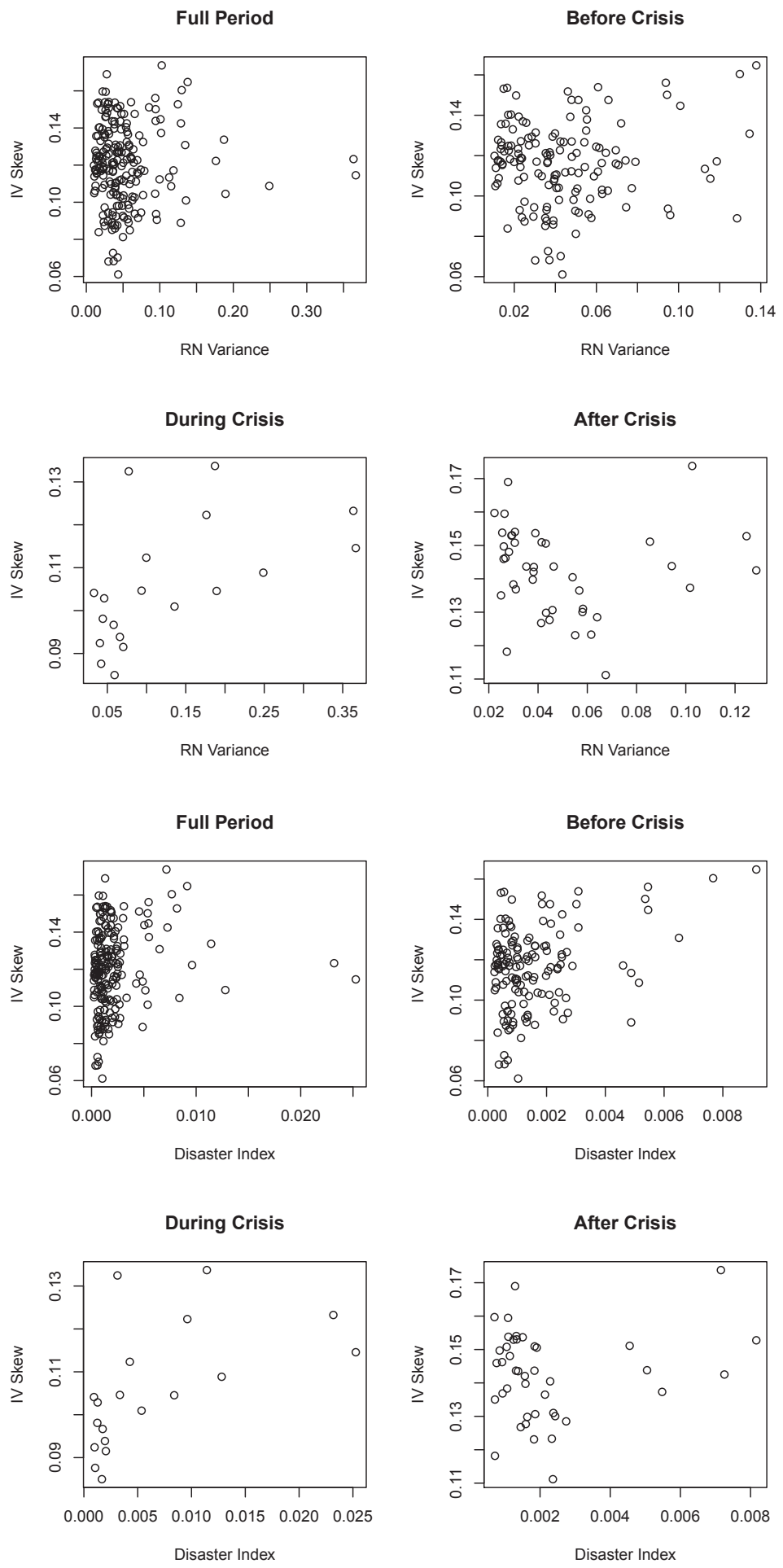
Figure 4: Time Series of Noise and the TED Spread as Measures of Financial Constraints
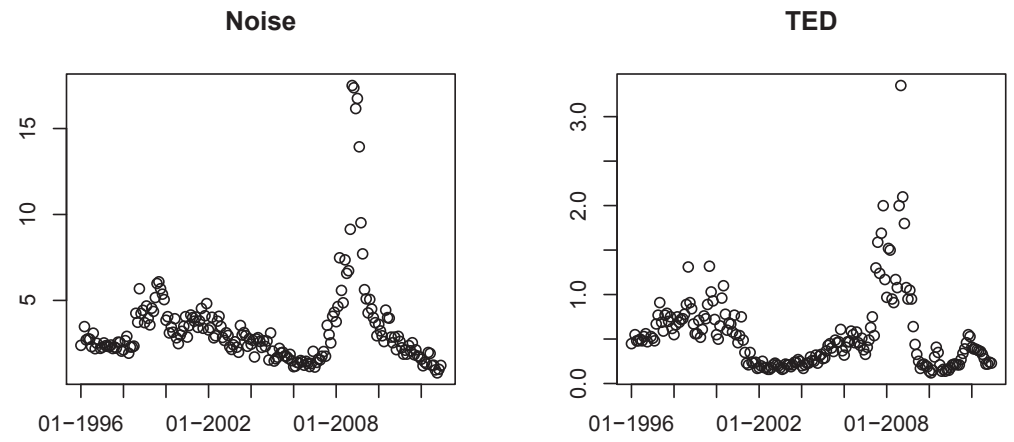

Figure 5: Model-Implied Supply and Demand for Put Options

$$
\sigma=0.04, p=0.05
$$
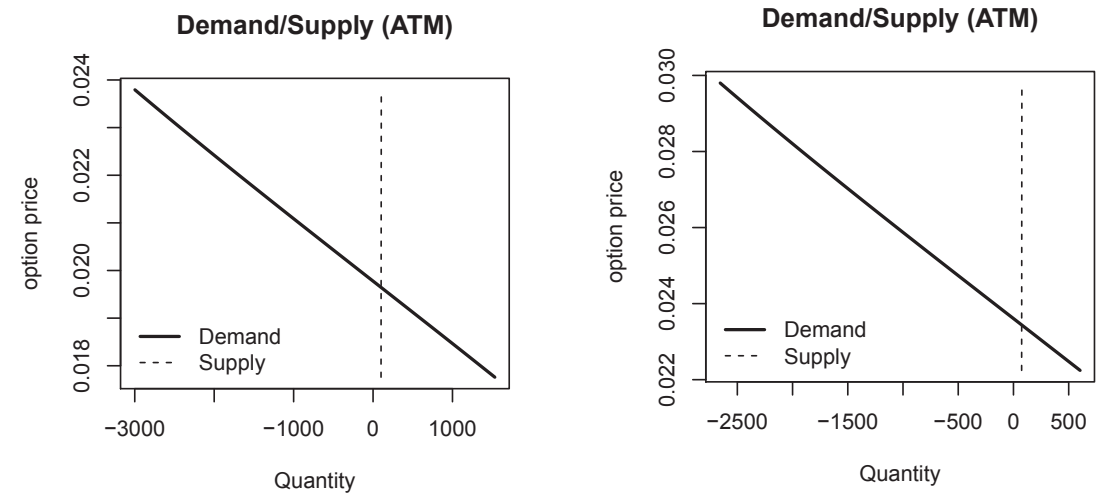

$$
\sigma=0.04, p=0.10
$$
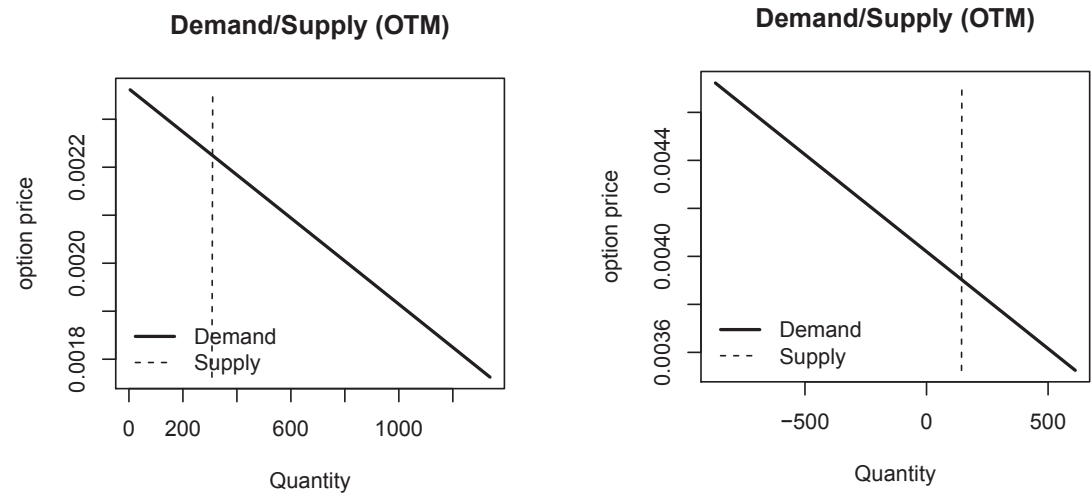
Figure 6: Model-Implied IV Skew as a Function of the Disaster Index and $R N$ variance

$$
\sigma=0.06
$$

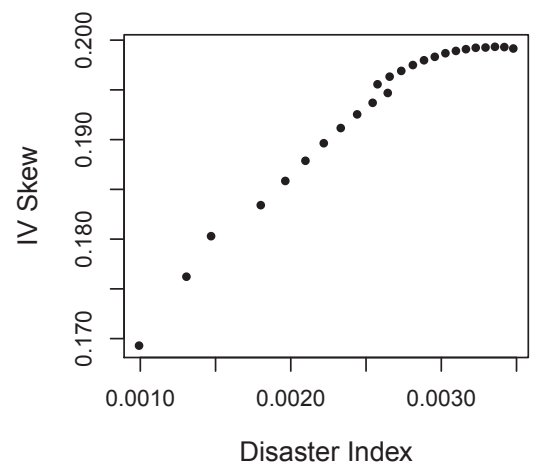

$$
p=0.06
$$

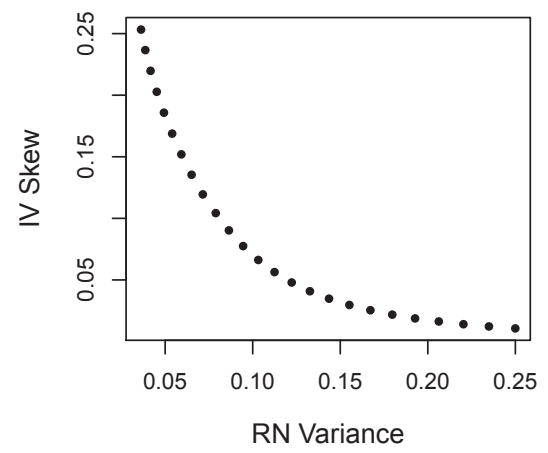

$$
\sigma=0.08
$$

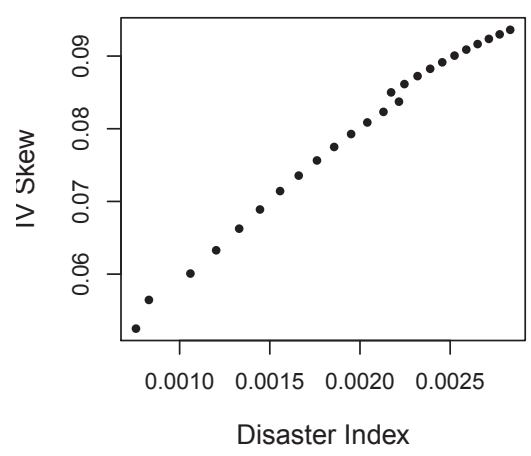

$$
p=0.10
$$

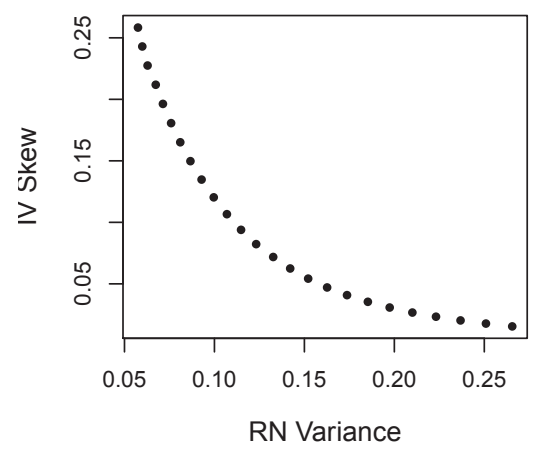


Figure 7: The Observed IV Skew versus the Observed Disaster Index and $R N$ variance
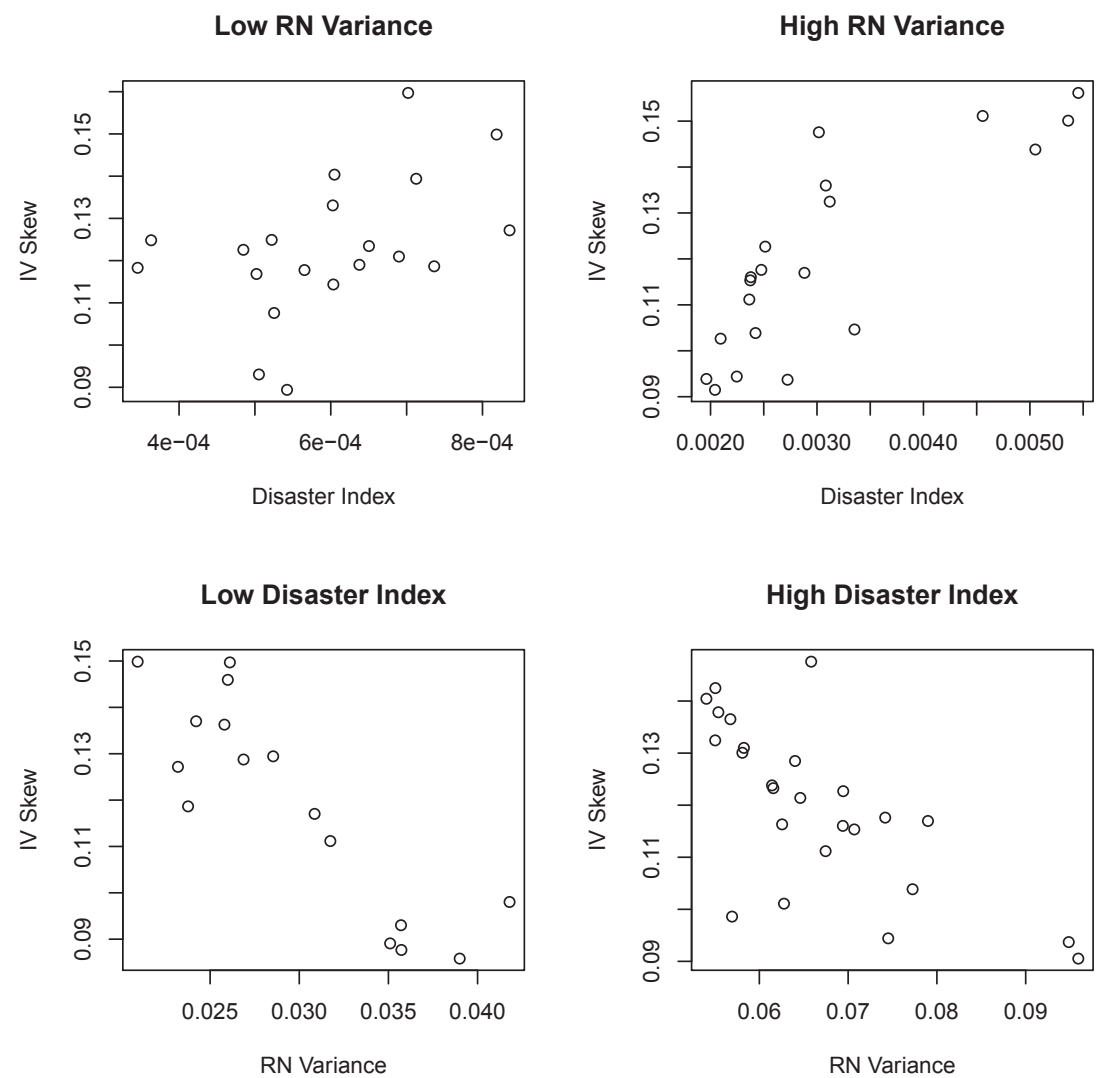
Figure 8: Model-Implied Net Buy of OTM Puts by Customers versus the Disaster Index and $R N$ variance

$\sigma=0.06$

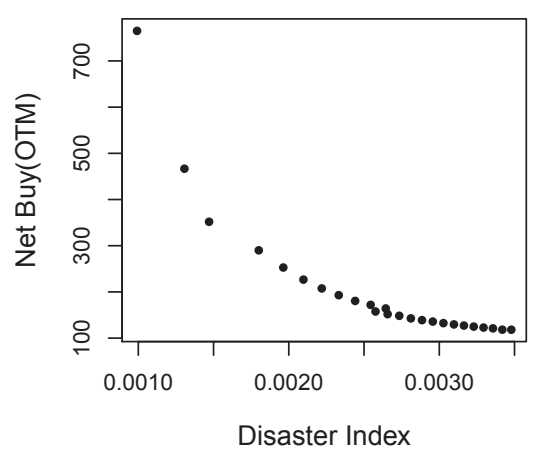

$p=0.06$

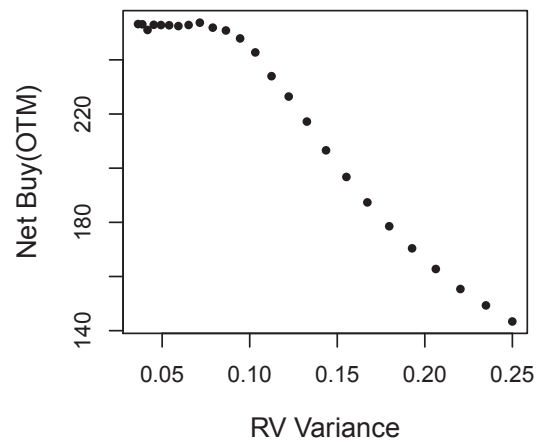

$\sigma=0.08$

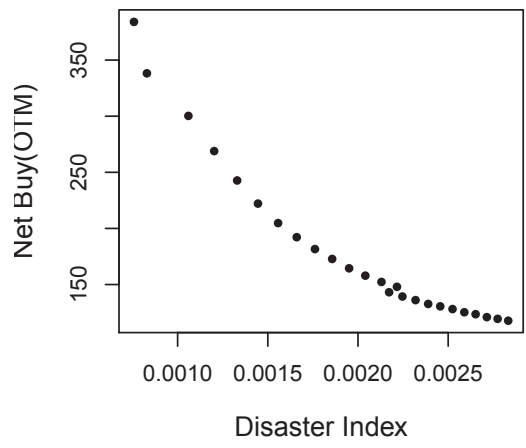

$p=0.10$

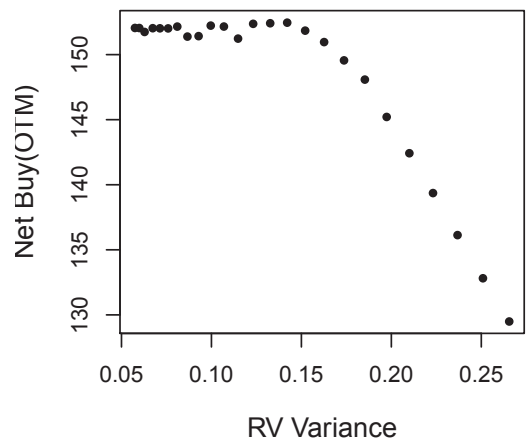


Figure 9: Model-Implied Net Buy of ATM Puts by Customers versus the Disaster Index and $R N$ variance

$\sigma=0.06$

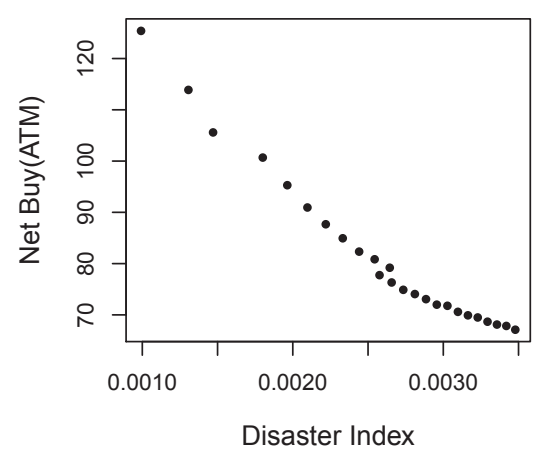

$p=0.06$

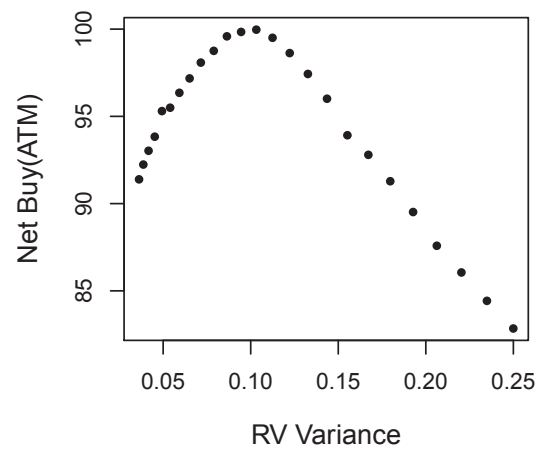

$\sigma=0.08$

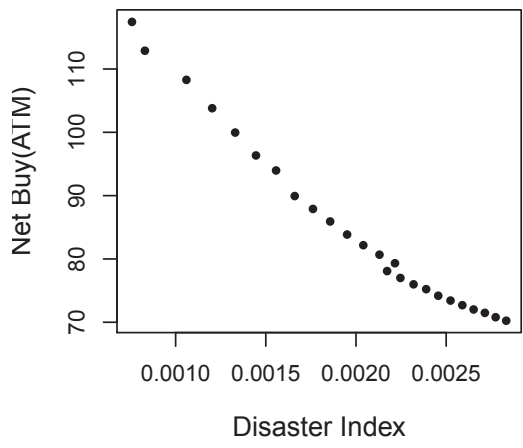

$p=0.10$

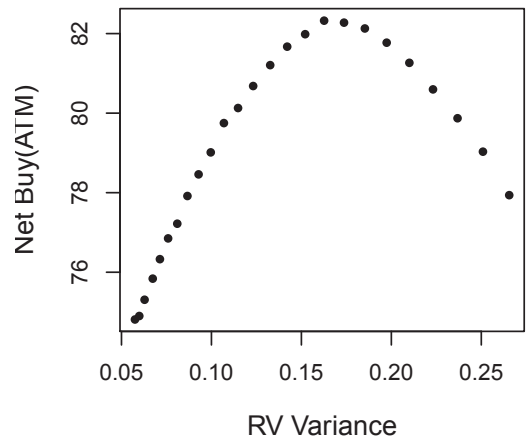


Figure 10: Time Series of the Observed Net Buy, $R N$ variance, and Disaster Index
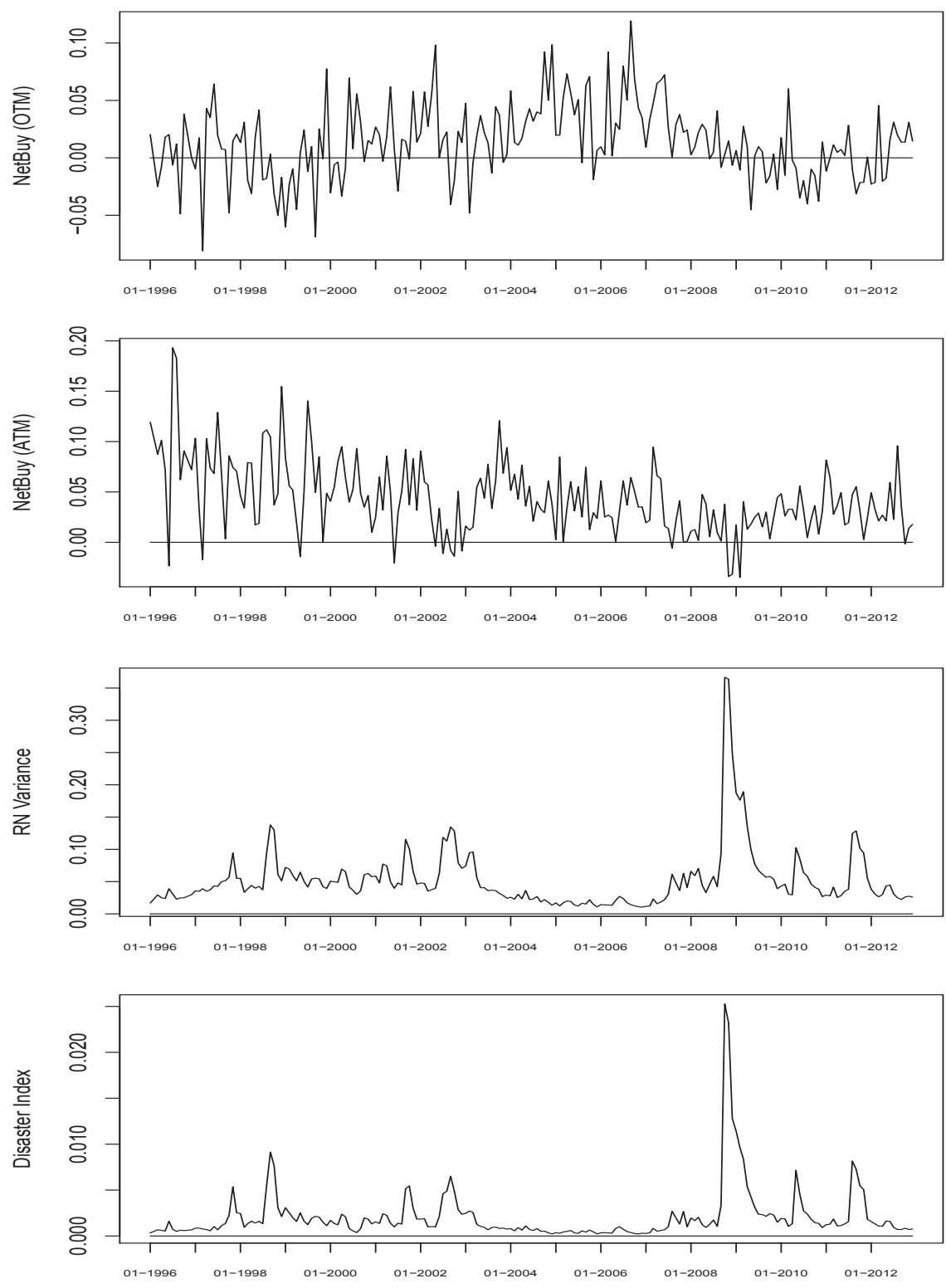
Figure 11: Model-Implied Net Buy versus the Price of OTM Puts in IV Units

$$
p=0.06
$$

$$
p=0.10
$$
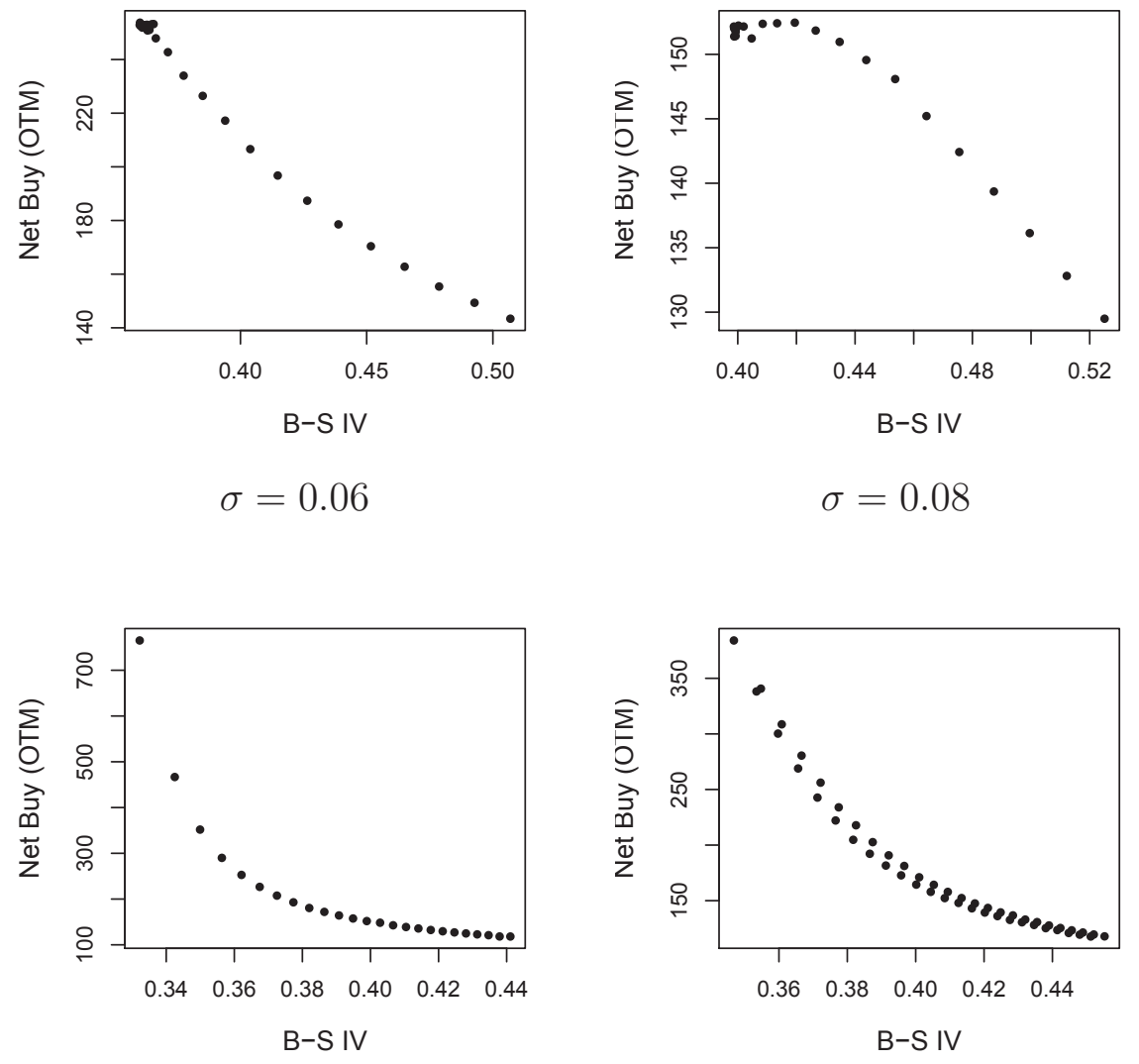
Figure 12: Observed Net Buy versus the Price of OTM Puts in IV Units
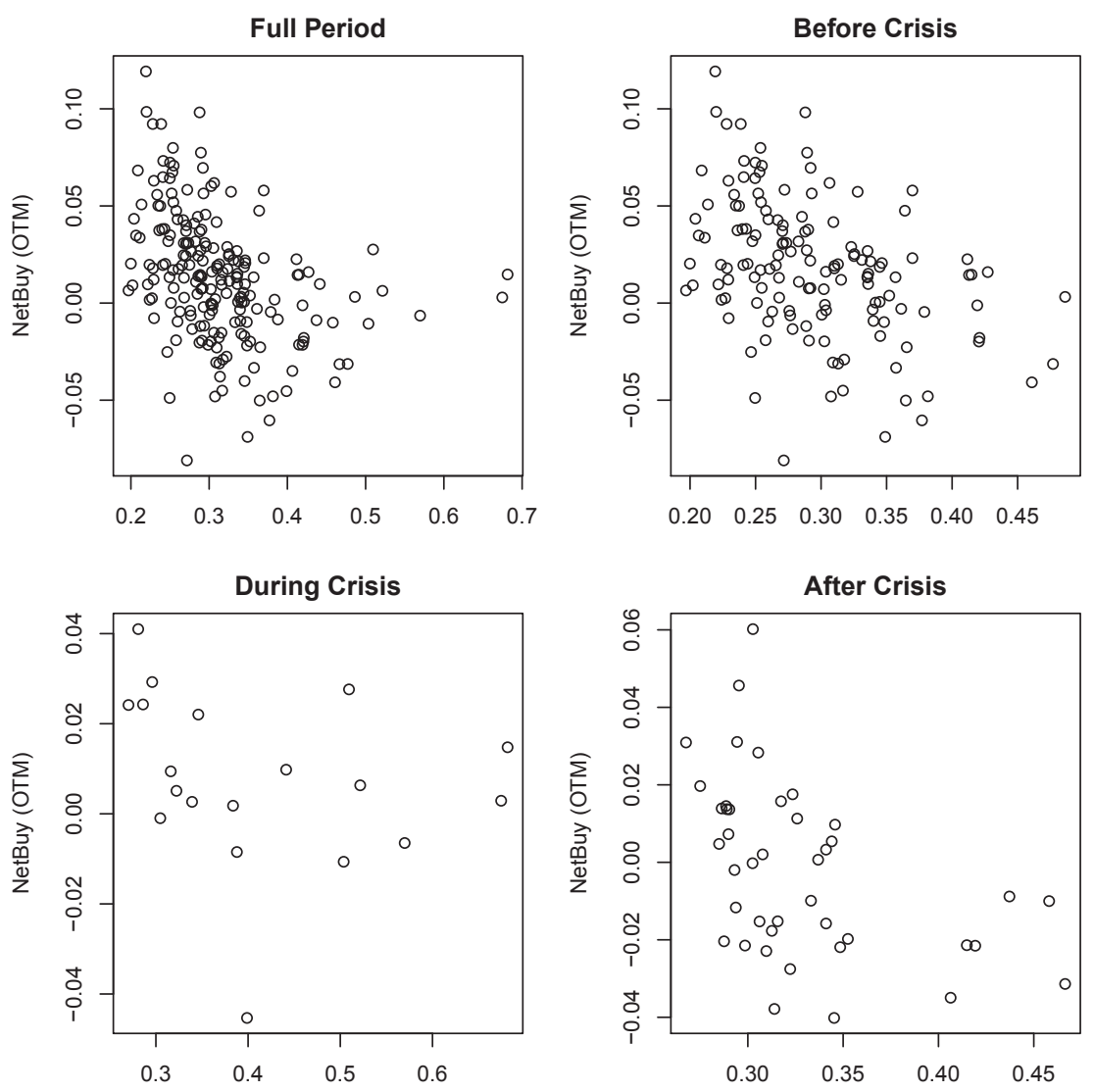
Figure 13: Model-Implied Net Buy versus the Price of ATM Puts in IV Units

$$
p=0.06
$$

$$
p=0.10
$$
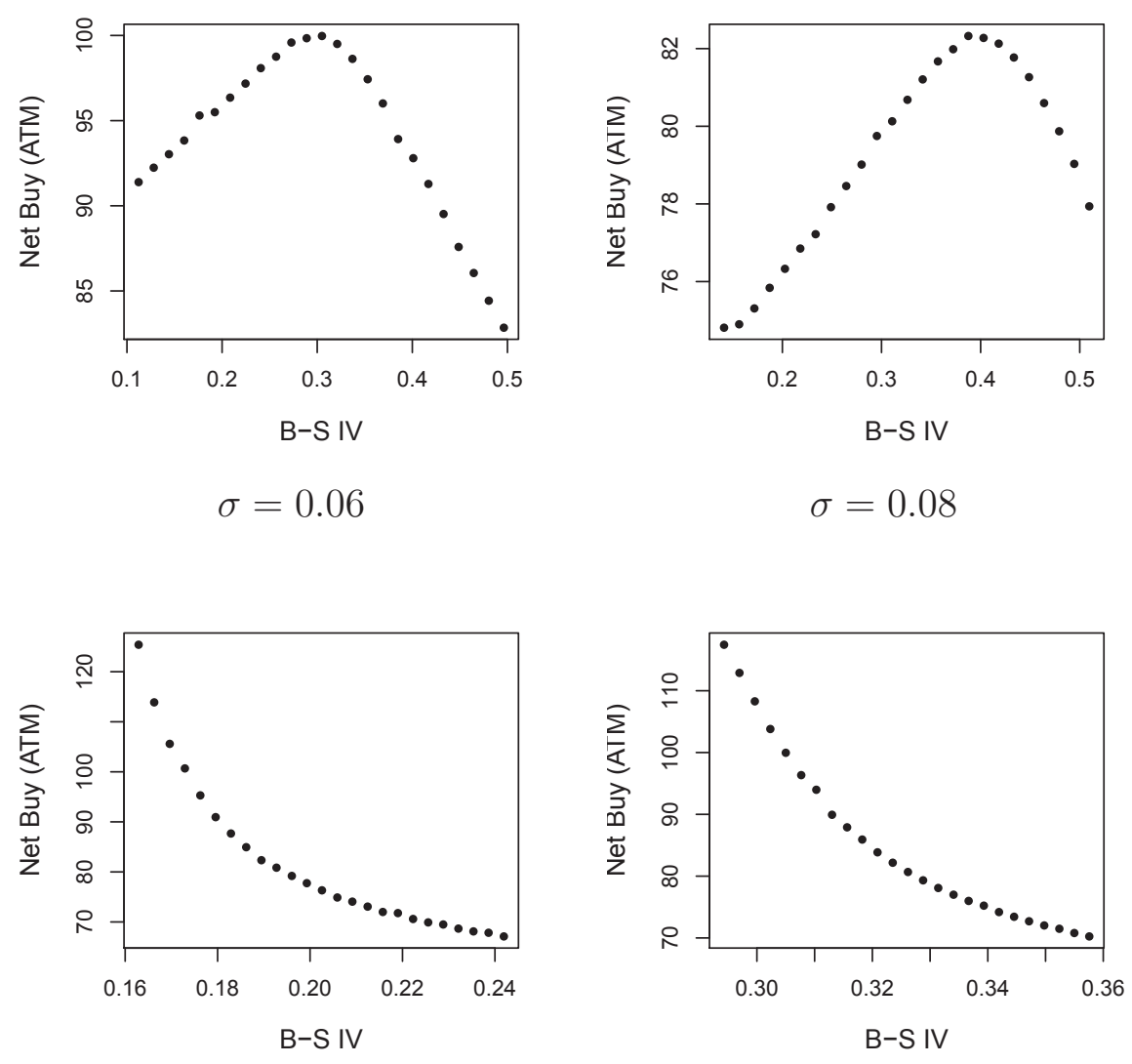
Figure 14: Observed Net Buy versus the Price of ATM Puts in IV Units
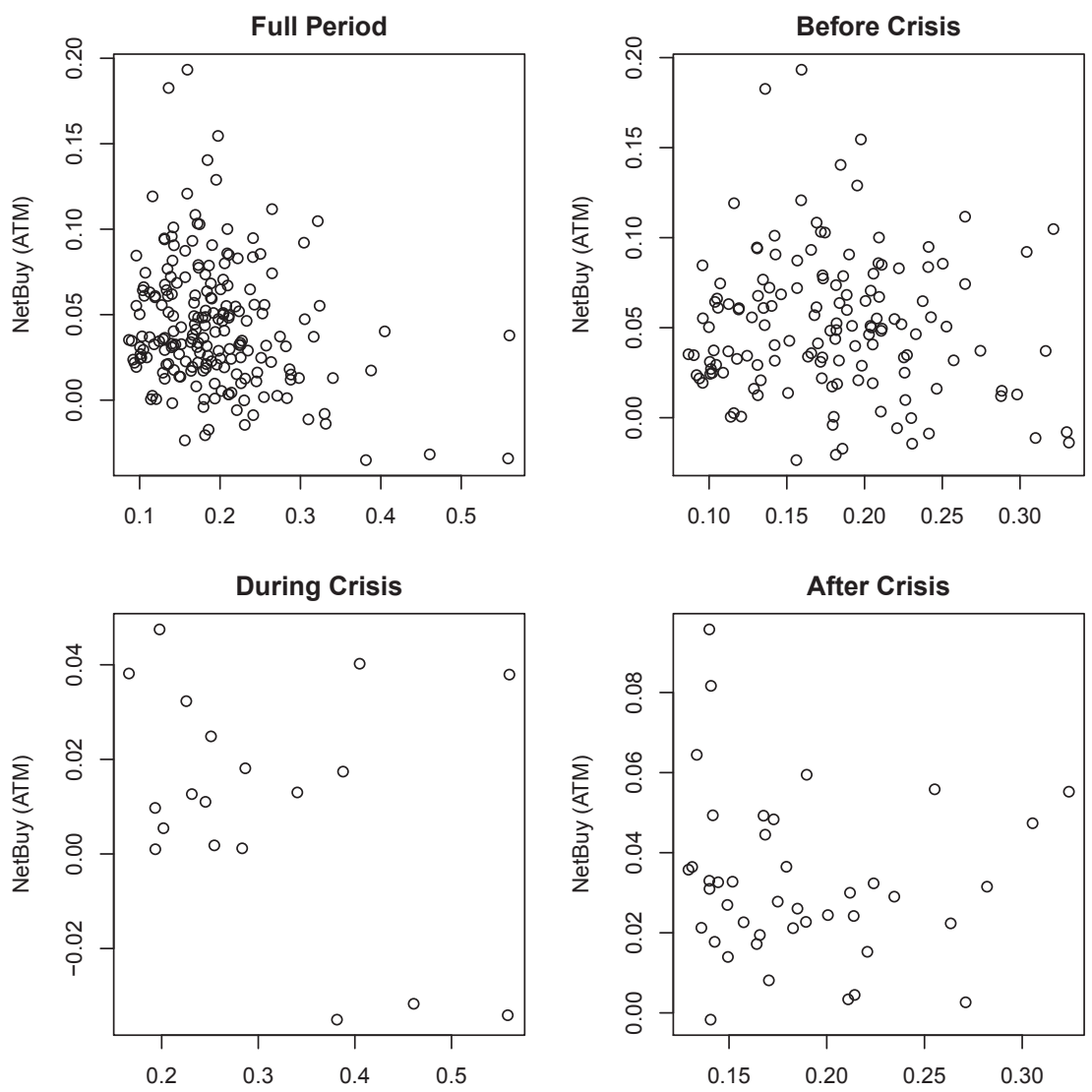
Figure 15: Model-Implied IV Skew versus the Net Buy of OTM Puts

$$
\sigma=0.06
$$
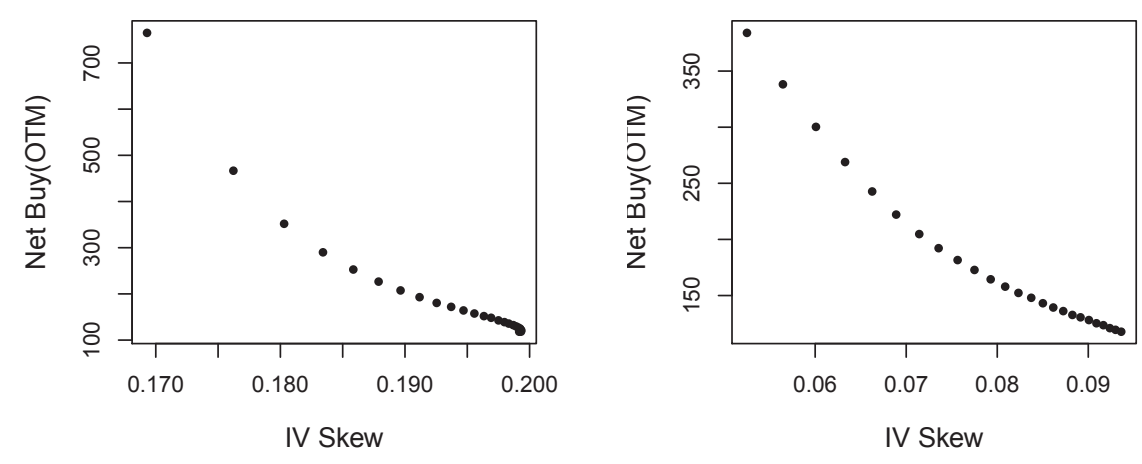

$$
p=0.06
$$
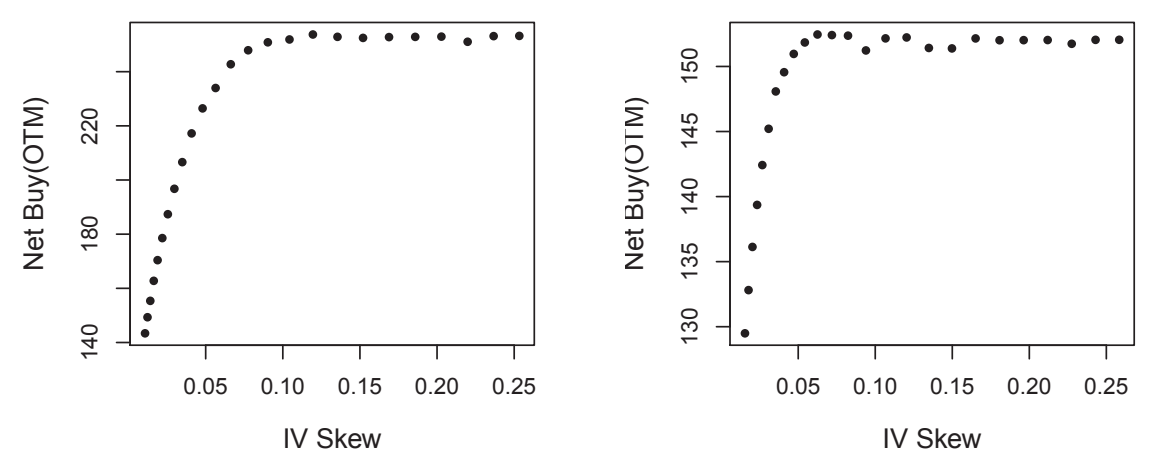
Figure 16: Model-Implied IV Skew versus the Net Buy of ATM Puts

$$
\sigma=0.06
$$

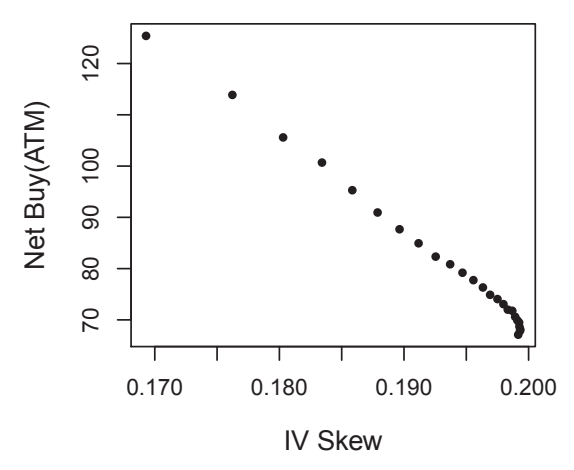

$$
p=0.06
$$

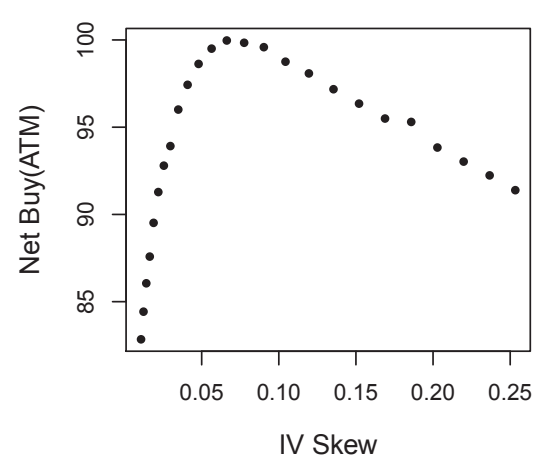

$$
\sigma=0.08
$$

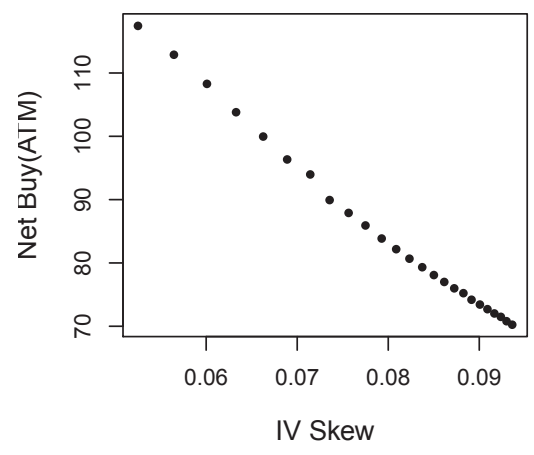

$$
p=0.10
$$

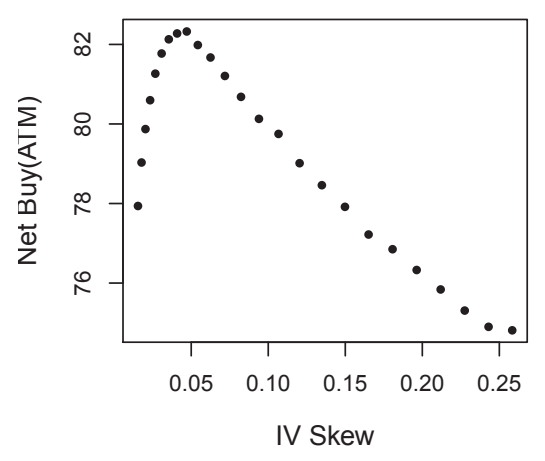


Figure 17: Observed IV Skew versus the Net Buy of OTM Puts
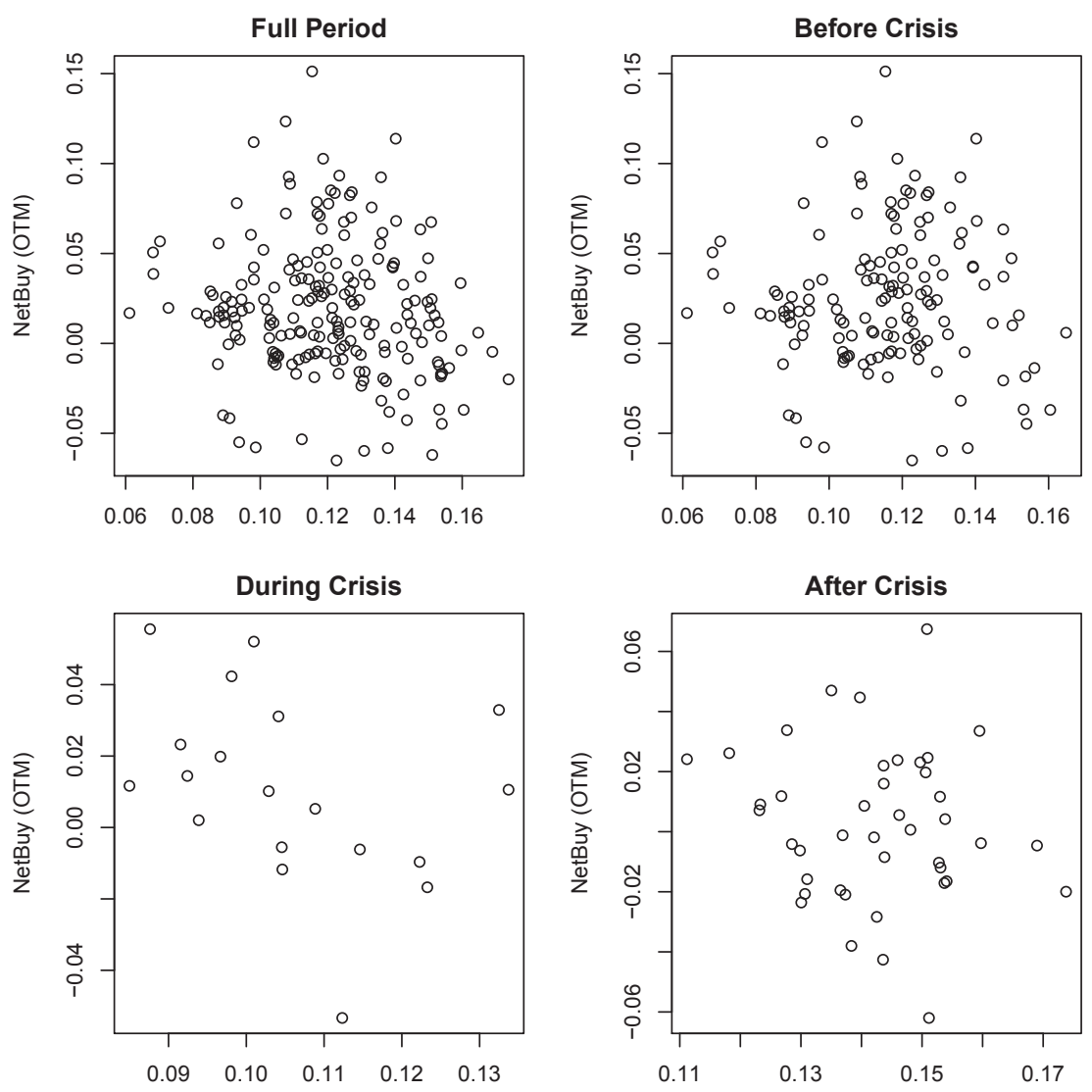
Figure 18: Observed IV Skew versus the Net Buy of ATM Puts
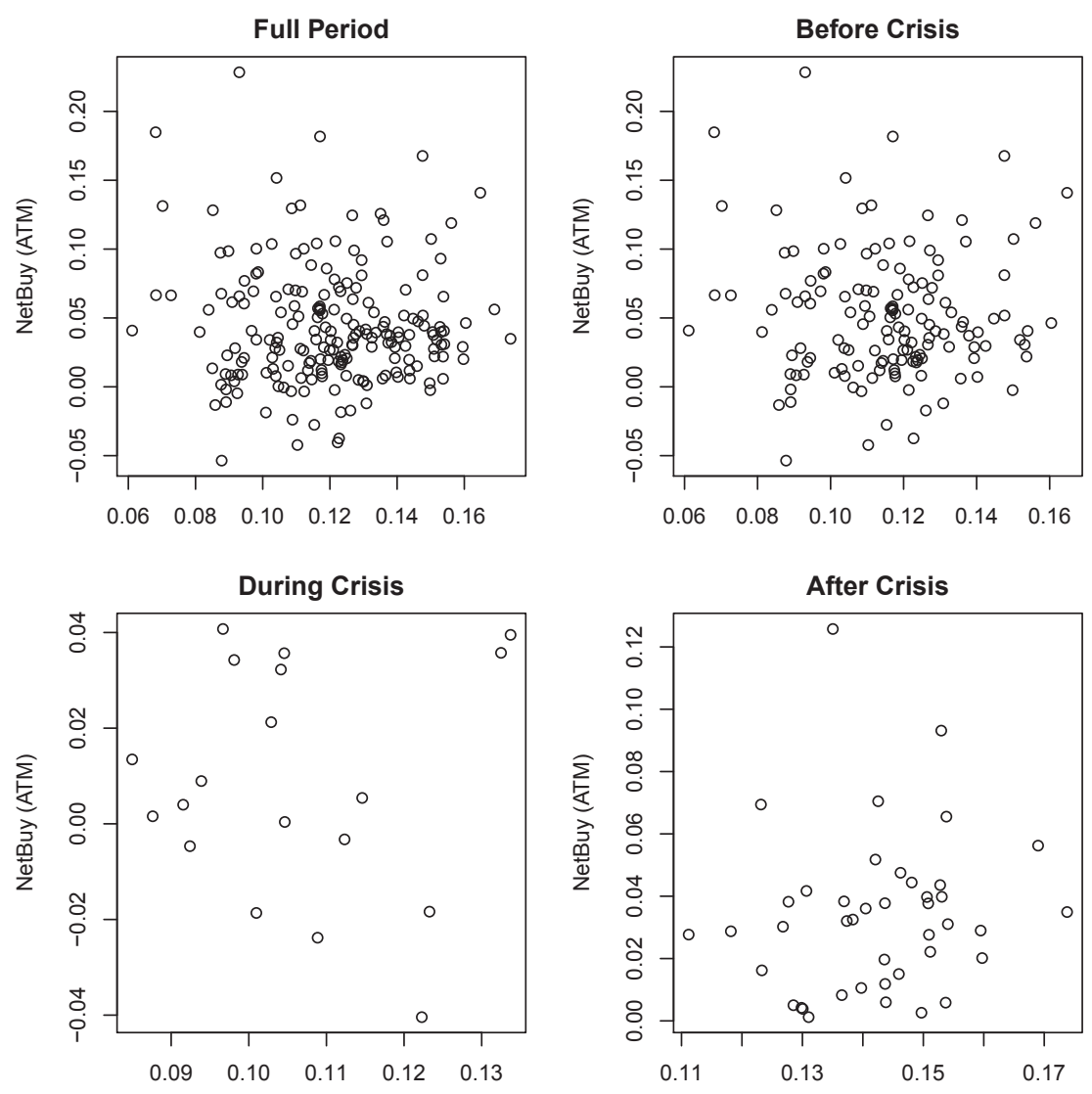